\title{
Extracellular Vesicles in Trypanosomatids: Host Cell Communication
}

\begin{abstract}
Ana Claudia Torrecilhas ${ }^{1 *}$, Rodrigo Pedro Soares ${ }^{2}$, Sergio Schenkman ${ }^{3}$, Christopher Fernández-Prada ${ }^{4}$ and Martin Olivier ${ }^{5 *}$
\end{abstract}

1 Departamento de Ciências Farmacêuticas, Federal University of Sao Paulo (UNIFESP), Diadema, Brazil, 2 Instituto René Rachou, FIOCRUZ-MG, Belo Horizonte, Brazil, ${ }^{3}$ Departamento de Microbiologia, Imunologia e Parasitologia, UNIFESP, São Paulo, Brazil, ${ }^{4}$ Faculty of Veterinary Medicine, Université de Montréal, St-Hyacinthe, QC, Canada, ${ }^{5}$ The Research Institute of the McGill University Health Centre, McGill University, Montréal, QC, Canada

Trypanosoma cruzi, Trypanosoma brucei and Leishmania (Trypanosomatidae: Kinetoplastida) are parasitic protozoan causing Chagas disease, African Trypanosomiasis and Leishmaniases worldwide. They are vector borne diseases transmitted by triatomine bugs, Tsetse fly, and sand flies, respectively. Those diseases cause enormous economic losses and morbidity affecting not only rural and poverty areas but are also spreading to urban areas. During the parasite-host interaction, those organisms release extracellular vesicles (EVs) that are crucial for the immunomodulatory events triggered by the parasites. EVs are involved in cell-cell communication and can act as important pro-inflammatory mediators. Therefore, interface between EVs and host immune responses are crucial for the immunopathological events that those diseases exhibit. Additionally, EVs from these organisms have a role in the invertebrate hosts digestive tracts prior to parasite transmission. This review summarizes the available data on how EVs from those medically important trypanosomatids affect their interaction with vertebrate and invertebrate hosts.

Keywords: Trypanosoma cruzi, Leishmania, inflammation, insect vector, innate immunity, skin pathology, Trypanosoma brucei, extracellular vesicles

\section{INTRODUCTION}

\section{Trypanosoma cruzi and Chagas' Disease}

American trypanosomiasis, popularly known as Chagas' disease (CD), whose etiologic agent is the flagellated protozoan Trypanosoma cruzi was first described by Carlos Chagas in 1909. CD is a neglected disease among the 17 tropical diseases. It is estimated that 8 million people are infected with $T$. cruzi in the world, the majority located in Latin America (WHO, 2019). In addition, 100 million people are at risk of infection and 2,000 deaths each year, circumstances that make $\mathrm{CD}$ a serious public health problem. In several Latin American countries, CD is controlled in blood banks and by elimination of vector to prevent transmission (Dias et al., 2002; Cavalcanti et al., 2009). Prevention in some countries like Bolivia is deficient (Coura and Vinas, 2010) and prevalence of the infection in Bolivia has been estimated at $6.8 \%$ (Luna et al., 2017) and (Bern, 2015). Nevertheless, oral transmission by ingestion of contaminated food, mainly açai fruit and sugar cane remains a source of new cases everywhere and congenital transmission 
(Brutus et al., 2008; Dias et al., 2008; Nóbrega et al., 2009; Bastos et al., 2010; Shikanai-Yasuda and Carvalho, 2012).

Despite being an endemic disease in Latin America, cases of $\mathrm{CD}$ have been reported in non-endemic regions such as North America (5,500 in Canada and 300,000 infected people in the United States), Europe (80,000 cases), Japan (3,000) and Australia (1,500) (Coura and Vinas, 2010; Perez et al., 2015). The occurrence of $\mathrm{CD}$ in these non-endemic regions creates a new epidemiological reality, which is due to population mobility, mainly due to migratory activities, as well as the lack of control in blood banks the source of infection in most of these cases (Coura and Vinas, 2010; Cura et al., 2013; Ries et al., 2016).

The invertebrate host is infected by ingesting trypomastigote forms present in the bloodstream of the mammalian host during hematophagy. In the vector gut, the parasite differentiates in epimastigotes, which subsequently multiply by binary division in the posterior intestine. Along the intestinal tract epimastigotes differentiate into metacyclic-trypomastigotes prior to release with urine and feces during a new blood meal. Such released metacyclictrypomastigotes are capable of infecting the mammalian host through mucosa or injured regions on the skin. Metacyclictrypomastigotes enter several cell types forming a parasitophorous vacuole and differentiate into amastigotes (de Carvalho and de Souza, 1989). Cytosolic amastigotes multiply by binary division and after seizing the host cell, differentiate into trypomastigotes, which erupts to the extracellular environment and reaches the bloodstream to continue the life cycle.

\section{Trypanosoma brucei and Human African Trypanosomiasis}

Trypanosoma brucei is the causative agent of Sleeping sickness or Human African Trypanosomiasis (HAT) and Nagana in cattle. It affects millions of people in countries at sub-Saharan Africa (Buscher et al., 2017). There are three subspecies group; T. brucei brucei (the agent of Nagana), T. brucei gambiense and T. brucei rhodesiense, which cause respectively the chronic and acute forms of the disease. These parasites are transmitted by Tsetse flies (Glossina spp.). The insect injects parasites into skin during the blood meal. From the bite, parasites enter the lymphatic system and then pass into the bloodstream. The bloodstream forms persist in blood causing anemia, and reach the central nervous system causing neurological disorders including encephalopathy that can lead to death if untreated (Buscher et al., 2017). Differently from T. cruzi, T. bruce i is an extracellular parasite and divides in the mammalian bloodstream, in the insects' gut and salivary glands. The bloodstream trypomastigotes surface is covered by a variant surface glycoprotein (VSG) that forms a coat around the parasite that protects it against host immune defenses (Vickerman and Luckins, 1969). There are about 2500 VSG different genes (Cross et al., 2014). Only one of them is expressed at each time and it is replaced allowing the parasite survival upon the establishment of a robust humoral responses (Mugnier et al., 2016; Aresta-Branco et al., 2019). Once the host establish an immune response, another VSG is expressed allowing the parasite to escape leading to chronic infection. In long-term infections, the parasite crosses the blood brain barrier and causes encephalopathy (Schwede and Carrington, 2010; Rudenko, 2011). In addition, parasite-derived molecules including surface metalloproteases (MSPs), phospholipase-C (PLC) and transferrin receptor (TfR) have been shown to play key roles in the interaction (Ponte-Sucre, 2016).

\section{Leishmania and Leishmaniasis}

Leishmaniases are a spectrum of diseases widely distributed in 98 countries in the world where approximately 350 million people are at risk of infection. It is considered be the World Health Organization (WHO) as the $6^{\text {th }}$ tropical disease. Its control involves basically the treatment of patients with Amphotericin $\mathrm{B}$ and Sb-based drugs depending on the country. However, the appearance of side-effects, discontinuation and drug resistance have been increasingly reported hindering chemotherapeutic control in several regions of the world (Kaye and Scott, 2011). Leishmaniasis may exhibit three distinct forms with variations: cutaneous leishmaniasis (CL), mucocutaneous leishmaniasis (MCL) and visceral leishmaniasis (VL). VL can be lethal if not treated in $90 \%$ of the cases, whereas CL lesions are of benign course but can be worsened by secondary infection. Although not lethal MCL is the most morbid type of infection destroying the tissues surrounding naso-oro-pharyngeal areas leading to disfiguration of the face. Main viscerotropic species include Leishmania donovani and Leishmania infantum, in the Old and New World, respectively. Dermotropic species are represented by Leishmania major/Leishmania tropica (Old World) and Leishmania braziliensis, Leishmania guyanensis, and Leishmania amazonensis (New World) (Herwaldt, 1999).

Leishmania parasites are transmitted through the bite of sand fly vector included in two main genera: Lutzomyia and Phlebotomus in the New and Old World, respectively (Elnaiem et al., 1994; Vexenat et al., 1994). Sand flies are pool feeder insects, inserting their mouth parts in the skin creating a pool where they take a bloodmeal and parasites are released. During their life cycle Leishmania parasites undergo several morpho-physiological modifications from an intracellular amastigote form to extracellular promastigotes in the midgut of the insect vector (Assis et al., 2012). In the sand fly midgut, during a process called metacyclogenesis, parasites differentiate into metacyclic promastigotes that are the infective forms injected in the vertebrate host's skin. In this proinflammatory milieu formed by sand fly-derived factors including saliva, exosomes, promastigote secretory gel (PSG), and bacteria, several cell types including macrophages and neutrophils are attracted to phagocyte the parasites. Inside those cells, metacyclic promastigotes lose their flagellum and become round-shaped forms so called amastigotes. Those divide until cell rupture and infection of the surrounding cells. During a next blood meal, the sand fly ingests macrophage containing amastigotes and the cycle continues (Peters et al., 2008; Atayde et al., 2015; Atayde et al., 2016; Dey et al., 2018).

\section{EXTRACELLULAR VESICLES}

EVs are particles formed by a lipid bilayer containing proteins and nucleic acids, which are derived and released by many types of cells (Yáñez-Mó et al., 2015; Devhare and Ray, 2018; Théry et al., 2018; Kao and Papoutsakis, 2019). Therefore, EVs can act as mediators in intercellular communication, either in prokaryotes or eukaryotes 
organisms (Abels and Breakefield, 2016). These particles modulate short- and long-range events, allowing cells to communicate even at long distances. EVs regulate physiological processes, such as blood coagulation, cell differentiation and inflammation, as well as pathological processes caused cancer, neurological, cardiovascular, and infectious diseases (Raposo and Stoorvogel, 2013; Yáñez-Mó et al., 2015; Kao and Papoutsakis, 2019). EVs are present in several biological fluids, such as: bile, feces, cerebrospinal fluid, nasal, synovial, uterine fluid, breast milk, amniotic fluid, saliva, blood, semen, and urine, as reviewed by Yanez-Mó et al. (2015).

According to "Minimal Information for Studies of Extracellular Vesicles" (MISEV2018), proposed by the International Society for Extracellular Vesicles (ISEV), the term "extracellular vesicles" is referred to all sub-populations of EVs, so it is recommended to use it collectively and universally (Théry et al., 2018). Among the various subtypes of extracellular vesicles, the particles can be defined as exosomes, microvesicles and apoptotic bodies, according to their origin, size, and constituents (Kandasamy et al., 2010; Yáñez-Mó, et al., 2015; Théry et al., 2018).

Exosomes are $50-100 \mathrm{~nm}$ in diameter released by eukaryotic cells during differentiation, stimulation and stresses (Mathivanan et al., 2010). They are formed in endosomes as multivesicular bodies and are released after exocytosis through fusion with the plasma membrane (Raposo and Stoorvogel, 2013; Hessvik and Llorente, 2018; Skotland et al., 2019). Exosomes released by B lymphocytes, mast cells, immature dendritic cells, platelets and cytotoxic $\mathrm{T}$ lymphocytes act in different physiological and pathological conditions (Théry et al., 2002; Kandasamy et al., 2010; Mathivanan et al., 2010; Raposo and Stoorvogel, 2013; Record, 2014; Record et al., 2014). They promote antigenic presentation (Andre et al., 2001; Wolfers et al., 2001; Théry et al., 2002; Chaput, Andre, et al., 2003a; Chaput, Schartz, et al., 2003b; Théry et al., 2009), signaling in cancer by promoting angiogenesis the immune response and remodeling of the surrounding parenchymal tissues to favor tumor progression (Becker et al., 2016). Exosomes are also involved in the formation of the pre-metastatic niche (Mathivanan et al., 2010; Rak, 2010; Araldi et al., 2012; Raposo and Stoorvogel, 2013; Ichikawa, 2015).

Microvesicles range in size from 50 to $1,000 \mathrm{~nm}$ in diameter and are generated from the outer buds of the cell's plasma membrane. The formation of these particles depends on the redistribution of phosphatidylserine in the membrane bilayer and on the reorganization of the cytoskeleton, mainly through the participation of actin-myosin (Akers et al., 2013). Previous treatment activated platelets with cytochalasin D inhibits the formation of microvesicles by reduction of actin polymerization (Crespin et al., 2009; Li et al., 2013). Microvesicles are involved in several functions. For example, they modulate coagulation and fetomaternal communication (Théry et al., 2018). Apoptotic bodies also formed by external buds from the plasma membrane but have a diameter between 50 and 5,000 $\mathrm{nm}$. They are released during the process of cell death, for example during apoptosis.

These different EV populations contain common sets of proteins, both of cytosolic origin, as heat shock proteins (Hsp 70 and 90) and membrane bound, as CD9, CD37, CD53, CD63, CD81, CD82, tetraspanins, and major histocompatibility complex I (MHC class I) and II (MHC class II). Tetraspanins are a family of proteins composed of four transmembrane domains (Théry et al., 2009; Li et al., 2013; Théry et al., 2018) and considered an exosomal marker, since they were first identified in exosomes derived from B lymphocytes. However, further studies have shown that tetraspanins are also found in several subpopulations of EVs (Zöller, 2009).

EVs are relevant for the communication between pathogens and host cells (Marcilla et al., 2014; Campos et al., 2015; Cwiklinski et al., 2015; Kim et al., 2015; Ancarola et al., 2017; Evans-Osses et al., 2017; Soares et al., 2017). Several protozoan parasites are capable of releasing EVs (Torrecilhas et al., 2012; Marcilla et al., 2014) including Trichomonas vaginalis, Plasmodium spp., T. brucei, and T. cruzi (da Silveira et al., 1979; Gonçalves et al., 1991; Trocoli Torrecilhas et al., 2009; Martin-Jaular et al., 2011; Cestari et al., 2012; Regev-Rudzki et al., 2013; Szempruch et al., 2016a; Szempruch et al., 2016b; Evans-Osses et al., 2017; Ofir-Birin et al., 2017; Ramirez et al., 2017; Ofir-Birin and Regev-Rudzki, 2019; Rossi et al., 2019; Cronemberger-Andrade et al., 2020), Leishmania spp. (Olivier et al., 2012; Hassani and Olivier, 2013; Hassani et al., 2014; Atayde et al., 2015; Atayde et al., 2016; Atayde et al., 2019a; Atayde et al., 2019b), and Toxoplasma gondii (Silva et al., 2018). These EVs have immunomodulating functions and affects the fate of the parasite in the host body (Torrecilhas et al., 2012; Campos et al., 2015; Borges et al., 2016).

\section{T. CRUZI EVs}

EVs are produced by the different life stages of T. cruzi (da Silveira et al., 1979; Gonçalves et al., 1991; Cestari et al., 2012; Bayer-Santos et al., 2013; Nogueira et al., 2015; Ramirez et al., 2017; Caeiro et al., 2018; Ribeiro et al., 2018; Paranaiba et al., 2019; Rossi et al., 2019) and participate in parasite host interactions (Marcilla et al., 2014; De Pablos et al., 2016; Diaz Lozano et al., 2017; Ramirez et al., 2017; Wyllie and Ramirez, 2017; de Pablos Torro et al., 2018; Retana Moreira et al., 2019; Cronemberger-Andrade et al., 2020). Figure 1 illustrates EVs in different T. cruzi life stages. The lack of studies of amastigote EVs is expected since it's intracellular location and the secreted material as it is often contaminated with host cell constituents. In both epimastigotes and trypomastigotes, EVs contain several surface components of the parasite involved in the parasite adhesion, invasion, and migration in the vector's gut (Nogueira et al., 2015; Ribeiro et al., 2018; Paranaiba et al., 2019; Cronemberger-Andrade et al., 2020). Trypomastigote EVs modulates T. cruzi infection and affect the protozoan ability to enter and escape the parasitophorous vacuole. Several signaling cascades are activated by EV components and modulate the cell responses (Burleigh and Andrews, 1995a; Burleigh and Andrews, 1995b; Burleigh et al., 1997; Burleigh and Andrews, 1998; Caler et al., 1998; Morty et al., 1999; Kima et al., 2000). For example, EVs affects host cell actin filaments, which allows migration of lysosomes and formation of the parasitophorous vacuole required for parasite internalization (Schenkman et al., 1992; Schenkman and Eichinger, 1993; Schenkman et al., 1993; Schenkman et al., 1994; Fernandes et al., 2011a; Fernandes et al., 2011b; Barrias et al., 2019; 


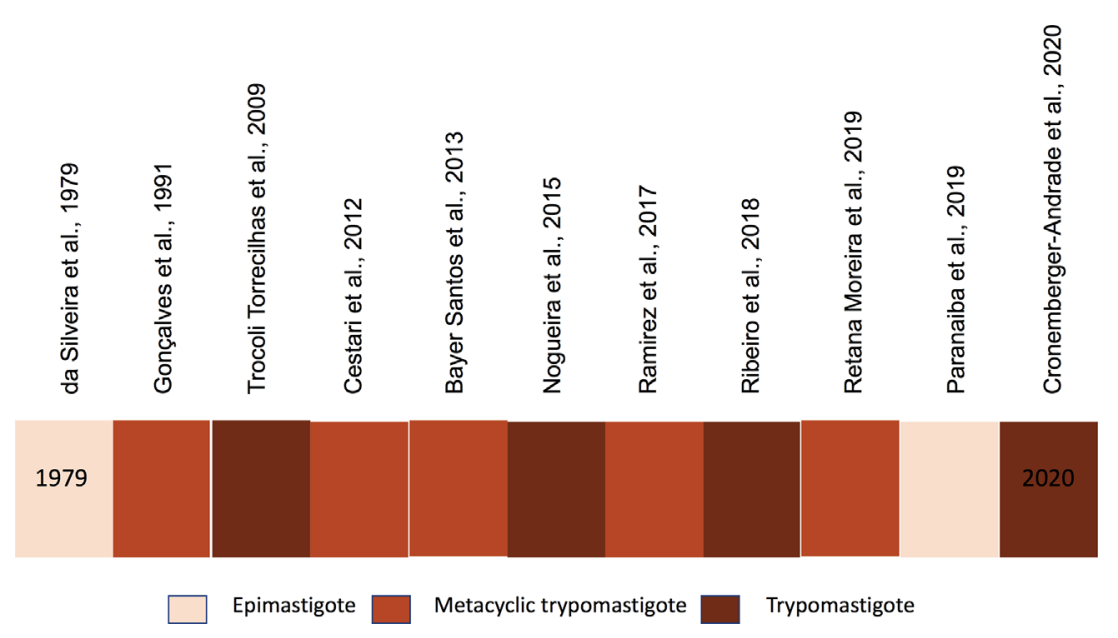

FIGURE 1 | Timeline of Trypanosoma cruzi EVs studies.

Reignault et al., 2019). EVs also modulate the invasion of metacyclic-trypomastigotes by inducing host cell signaling through tyrosine phosphorylation and nucleation of actin filaments (Yoshida and Cortez, 2008).

\section{Proteomic Analysis of T. cruzi EVs}

EVs isolated from $T$. cruzi trypomastigotes derived from mammalian cells contain most of the parasite cell-surface proteins, including major surface glycoproteins that resemble to mucins (Ribeiro et al., 2018) (Table 1). These glycoproteins are encoded by more than a thousand genes many of them containing heterogenous sequences rich in proline and threonine with $\mathrm{N}$-acetyl glucosamine $O$-linked oligosaccharides that can be either sialylated by the parasite trans-sialidase (TS), or modified by $\alpha$-galactose (McConville et al., 1990; Almeida et al., 2000; Soares et al., 2012). These carbohydrate moieties are involved in the interaction of the parasite with mammalian host cells (Buscaglia et al., 1998; Almeida et al., 2000; Almeida and Gazzinelli, 2001; Buscaglia et al., 2004; Lantos et al., 2016).

Trypomastigote EVs also contain N-linked glycoproteins, which are encoded by hundreds of different genes (TS/GP85 superfamily) (Ribeiro et al., 2018) (Table 1). The family encodes mostly proteins known as Tc85, GP85, complement-regulatory protein (CRP), flagellum-associated protein, $85 \mathrm{kDa}$ surface antigen, c71 surface protein (Freitas et al., 2011). It is proposed that their lectin like domains in the C-terminal domain can interact with different types of surface molecules of host cells. For example, some of these glycoproteins interact with cytokeratins exposed in the mammalian surface. The superfamily includes a minor population of proteins with trans-sialidase (TS) activity, some of them with an additional 12 amino acid repeats in the Cterminus named shed-acute-phase-antigen (SAPA). There are

TABLE 1 | Extracellular vesicles isolated from Trypanosomatid: features, cargoes, effects on host parasite interaction.

\begin{tabular}{|c|c|c|c|}
\hline Trypanosomatid & Cargoes/molecules & Effect on host & References \\
\hline T. cruzi & $\begin{array}{l}\text { Trans-sialidase Mucin } \\
\text { Cruzipain } \\
\text { GP85 } \\
\text { RNA }^{*} \\
\text { GP82 }^{\star \star} \\
\text { Lipids }^{\star \star \star} \\
\text { SAPA } \\
\text { MASP }\end{array}$ & $\begin{array}{l}\text { i) Induce innate immune response via TLR2. } \\
\text { ii) Increase Invasion of the parasite } \\
\text { iii) Parasites escaping the complement attack modulate TGF- } \beta \text {-bearing } \\
\text { EVs released from host cells. } \\
\text { iv) Immunomodulation, cell attachment and regulation of host complement } \\
\text { system. }\end{array}$ & $\begin{array}{c}\text { (Cestari et al., 2012; Campos et al., 2015; } \\
\text { Nogueira et al., 2015; Ramirez et al., 2017; } \\
\text { Ribeiro et al., 2018) }\end{array}$ \\
\hline T. brucei & $\begin{array}{l}\text { VSG } \\
\text { Protease } \\
\text { MSPs } \\
\text { PLC }\end{array}$ & i) Evasion from the host immune system and increase invasion BBB. & (Szempruch et al., 2016) \\
\hline $\begin{array}{l}\text { L. donovani } \\
\text { L. infantum } \\
\text { L. mexicana }\end{array}$ & $\begin{array}{l}\text { GP63 } \\
\text { LPG } \\
\text { HSP }\end{array}$ & $\begin{array}{l}\text { i) Parasite evasion by altering complement mediated lysis and promoting } \\
\text { parasite phagocytosis. }\end{array}$ & (Silverman et al. 2010a; Hassani et al., 2011) \\
\hline
\end{tabular}

MSPS, Major surface proteases; PLC, phospholipase-C; BBB, Blood Brain Barrier; VSG, Variant Surface glycoprotein; LPG, lipophosphoglycan.

${ }^{*}$ RNA; ${ }^{* *}$ GP82 and ${ }^{* * *}$ Lipid, are unpublished data.

SAPA, Shed-Acute-phase-antigen; MASP, Mucin-Associated Surface Protein. 
two distinct populations of trans-sialidase differentiated by the substitution of a tyrosine residue by a histidine in the active site of the sialidase domain. This substitution abrogates the hydrolytic activity, but the protein is still able to bind sialylated residues. One of the main targets of these inactive and active trans-sialidase is the CD43, a sialoglycoprotein in hemopoietic cells (Freire-de-Lima et al., 2010), which particularly relevant in the myocarditis development in experimental CD (Alisson-Silva et al., 2019). Mucins and TS/GP85 glycoproteins are associated to the surface of T. cruzi through glycosylphosphatidylinositol (GPI) anchors (McConville et al., 1990; Pontes de Carvalho et al., 1993; Schenkman et al., 1993; Schneider et al., 1993; Izquierdo et al., 2015). The GPI moiety is recognized by Toll 2 (TLR2) and 4 (TLR4) receptors in immune cells (Camargo et al., 1997; Almeida et al., 1999; Almeida et al., 2000; Almeida and Gazzinelli, 2001; Campos et al., 2001; Procópio et al., 2002; Campos et al., 2004; Monteiro et al., 2006). EVs, which carry these GPI-containing molecules are able to induce inflammatory responses in murine macrophages via TLR2, triggering the synthesis of pro-inflammatory cytokines, such as TNF- $\alpha$ and IL-12, in addition to the production of nitric oxide (NO) (Nogueira et al., 2015; Cronemberger-Andrade et al., 2020). Consistent with these observations, EVs from Y strain also triggered the production of those cytokines and lipid body formation via Prostaglandin E2 (PGE2) (Lovo-Martins et al., 2018). Furthermore, other constituents such as the T. cruzi Trypomastigote Alanine Valine and Serine rich proteins (TcTASV-C) might also induce EVs signaling as it is largely present in EVs from trypomastigotes from different DTUs (I, II, and VI) (de Pablos Torro et al., 2018).

Cysteine-proteases such as cruzipain and the surface metalloproteases, named GP63 that modulate several processes in the host cells are also present in trypomastigotes EVs. These proteases are involved in several process affecting the infection, including the process of parasite internalization and survival (Scharfstein and Lima, 2008; Alvarez et al., 2012; Watanabe Costa et al., 2016). In addition, cruzipain is also involved in the activation of the host's immune system (Duschak and Couto, 2009; Acosta et al., 2012; Soprano et al., 2018). Therefore, these peptidases can act independently of the presence of the parasite on the host through circulating EVs. Proteins from cytoskeletal proteins, such as tubulin, heat shock proteins, and other soluble proteins, were also detected in the total EV fractions (Ribeiro et al., 2018).

Another class of proteins found in some proteomic analysis of EVs are cytoskeleton-related proteins, such $\alpha$ - and $\beta$-tubulin, kinesins, and myosins. These cytoskeleton proteins are usually of exosomes from eukaryotic cells. We also identified other proteins related to exosomes and vacuoles, such as heat-shock protein 85 (HSP85), elongation factor 1-alpha, glyceraldehyde 3-phosphate dehydrogenase (GAPDH), vacuolar ATP synthase subunit B, and tetratric-peptide-repeat (TPR) protein (Théry et al., 2018; Doyle and Wang, 2019).

EVs of metacyclic-trypomastigotes also contain major surface components of the parasite, including the gp35/50 mucin-like glycoproteins and members of trans-sialidase family of glycoproteins (Bayer-Santos et al., 2013). These surface components participate in the cell adhesion and invasion of the metacyclic-trypomastigotes (Schenkman et al., 1993; Santori et al., 1996; Neira et al., 2002; Neira et al., 2003; Eickhoff et al., 2010; Cortez et al., 2012; Cortez et al., 2014;
Cordero et al., 2019). Gp82 glycoprotein, a metacyclic specific member of the gp85/trans-sialidase family activates mTOR signaling cascades that allow lysosome migration and fusion with the parasitophorous vacuole producing acidification and parasite escape to the cytosol (Cortez et al., 2012; Cortez et al., 2014; Cordero et al., 2019). It also binds to LAMP-2 receptor favoring parasite internalization (Andrade and Andrews, 2005; Albertti et al., 2010; Andrade, 2019). However, previous incubation with EVs released by metacyclic-trypomastigotes decrease invasion of HeLa cells mediated by gp90, another member of the family (Yoshida et al., 1990) and inhibits cell invasion (Rodrigues et al., 2017). These proteins are also released in the soluble form by the endogenous activity of a GPI phospholipase C activity (Schenkman et al., 1988). Therefore, EVs in this stage provide signals that can either increase up to10 times cell invasion. One possibility is that this combination provides specific responses among different host cells and tissues. EVs from epimastigote and metacyclic-trypomastigote forms also contain mucin-like surface glycoproteins GP35/50, typical of the insect stages of the parasite (Schenkman et al., 1993; Bayer-Santos et al., 2013). These molecules act as adhesion molecule in the interaction of the parasite with the host (Ruiz et al., 1993). Therefore, GP35/50 in EVs could modulate their interaction with host cells. Another protein in the epimastigote EVs is the flagellum calcium binding protein (FCaBP), which is linked to internal membrane leaf of the parasite and modulates several proteins through $\mathrm{Ca}^{2+}$ signaling (Buchanan et al., 2005). In fact, microvesicles isolated from metacyclic-trypomastigotes forms enhance communication between T. cruzi and host cell promoting invasion (Ramirez et al., 2017). These vesicles inhibit complement-mediated lysis and enhance invasion of Vero cells.

\section{EVs Cargoes Lipids and Nucleic Acids}

Studies of non-protein components in EVs are still in their infancy and a limited number of publications is available for trypanosomatids. This provides a promising field to be explored by researchers. Purified EVs of different T. cruzi isolates contains phospholipids including cardiolipin, sphingomyelin, phosphatidylcholine, phosphatidylinositol, phosphatidylcholine, phosphatidylethanolamine and phosphatidylserine. Also, they possess an unidentified non-polar component, as detected after extraction and thin-layer chromatography (unpublished). Several fatty acids were detected after extraction of total lipids by gas chromatography and mass spectroscopy (GC-MS) with a large variation (25 to 8 ) according to the strain. The four common compounds species were: 5-octadecene, 1-octadecene, 1hexadecene, and 3-heptadecene with 1-Docosene, But-2-enoic acid, amide, 3-methyl-N-metallyl-, heneicosane, tritetracontane found in the Y strain but not in the YuYu (unpublished). As the fatty acids are critical to induce pro-inflammatory responses, these EV components may be important for TLR activation. We also detected RNA, but not DNA in EVs isolated from trypomastigote but their nature and composition should be further investigated. Epimastigotes were also found to release fragments of tRNA that could modify host cells behavior (Garcia-Silva et al., 2014).

\section{Internalization of EVs Into the Target Cells}

Initially, our group showed that $T$. cruzi EVs could be rapidly internalized in vitro by cells suggesting that they could also activate 
intracellular pathways in the host (Torrecilhas et al., 2012). Further, we showed that those EVs could also act as TLR2 agonists suggesting that perhaps both mechanisms could occur (Nogueira et al., 2015). Recently, T. cruzi EVs incubated with Toll-like-receptor 2 (TLR2)transfected $\mathrm{CHO}$ cells increased invasion by the parasite. In parallel, they elicit the translocation of NF- $\mathrm{KB}$ and gene expression of proinflammatory cytokines (TNF- $\alpha$, IL- 6 and IL- $1 \beta$ ), and STAT- 1 and STAT-3 signaling pathways (Cronemberger-Andrade et al., 2020). Since GPI-anchored proteins in EVs are TLR2 ligands, this activation is probably one of the mechanisms triggered by EVs.

\section{Role of T. cruzi EVs on Host Responses}

Incubation of T. cruzi EVs, or parasite infection of host cells induce several responses, including the increased secretion of EVs by host cells (Ramirez et al., 2017; Choudhuri and Garg, 2020; Cronemberger-Andrade et al., 2020). The host EVs contain some parasite antigens and nucleic acids that possible elicit activation of intracellular Toll receptors and increase the inflammatory response. Interestingly, the presence of the remaining parasite DNA processed by Poly(ADP-ribose) polymerase 1 (PARP1) and cyclic GMP-AMP synthase (cGAS) amplified the inflammatory signal.

The interaction of trypomastigote EVs with host cells with epithelial cells or macrophages occurs rapidly and after $15 \mathrm{~min}$ parasite proteins are detected by specific antibodies and increase in cytosolic $\mathrm{Ca}^{2+}$ (unpublished). This finding is related to increased invasion by the parasite after incubation with the parasite EVs (Cronemberger-Andrade et al., 2020) in agreement with the requirement for $\mathrm{Ca}^{2+}$ mobilization during cell invasion (Burleigh and Andrews, 1998). The EVs could also affect the host cell surface cytoskeleton and that might facilitate parasite internalization.

\section{In Vivo Studies}

Mice that received EVs prior to infection developed severe heart pathology, with intense inflammatory reaction and higher number of intracellular amastigotes (Trocoli Torrecilhas et al., 2009). The inflammatory infiltrates contain CD4+ and CD8+ T lymphocytes and macrophages and decrease of iNOS spots expression. Also, IL4 and IL-10 mRNAs in the heart from animals treated with EVs isolated from parasites. The molecules present on EVs act as primers of the host immune system, facilitating the establishment of the infection and inflammation in the animal model. The modulation of prostaglandin is also modulated by pre-injection of parasite EVs (Lovo-Martins et al., 2018).

T. cruzi EVs derived from epimastigotes were evaluated during interaction of the parasite with triatomine bugs Rhodnius prolixus and Triatoma infestans. EVs were artificially offered to the insects prior to infection with epimastigotes. Pre-feeding with EVs delayed early parasite migration to the rectum in $R$. prolixus, but not in T. infestans, affecting parasite-host interaction during the initial events of infection in the invertebrate's gut (Paranaiba et al., 2019). However, the mechanisms underlying parasite retainment remain to be explored.

Therefore, the release of EVs reflects a strategy developed by the parasite to secrete its main surface components that act, for example, facilitating processes such as adhesion and invasion to the host cell (Fernandes, Andrade, et al., 2011a; Fernandes, Cortez, et al., 2011b; Cronemberger-Andrade et al., 2020), as well as evading the host immune system (Cestari et al., 2012). EVs modify the host allowing a more favorable environment for parasite survival and, consequently, to promote infection and possible disease progression (Trocoli Torrecilhas et al., 2009; Cestari et al., 2012; Torrecilhas et al., 2012). It is relevant that different parasite isolates of $T$. cruzi showed surface variations, and most likely different EVs population, that influence the differential activation of the immune response in the host. In fact, EVs of two different strains of the parasite ( $\mathrm{Y}$ and $\mathrm{YuYu}$ ) have qualitative and quantitative differences in content, which directly interfere with virulence and the rate of infectivity in different cell types (Ribeiro et al., 2018).

Our finding that several glycoconjugates and other virulence factors are released as main components of EVs, indicates that these vesicles could play a major role in the interaction with host cells. Those key elements may represent novel targets for chemotherapy and vaccines.

\section{Trypanosoma brucei EVs}

T. brucei bloodstream forms nanotubes originated from the flagellar pocket that breakdown into EVs that contain molecules that are present in the parasite surface (Geiger et al., 2010). These EVs contain mostly VSGs but are particularly enriched in flagellar proteins and proteins involved in the parasite virulence factors (Szempruch et al., 2016a; Szempruch et al., 2016b). These EVs are in the range of 50 to $100 \mathrm{~nm}$ in diameter, which correspond to exosomes size. The proteins identified in the secretome of T. $b$. rhodesiensis are also related to the parasite survival strategies as they contain the serum resistance-associated protein (SRA) that allow the parasite to survive in human blood (Geiger et al., 2010). It has been shown that EVs derived from T. brucei are highly fusogenic and transfer lipids and VSG glycoproteins to erythrocytes. This alteration in erythrocytes membrane results in its phagocytosis by macrophages in the liver and spleen leading to anemia (Szempruch et al., 2016a; Szempruch et al., 2016b). The EVs released by the parasite may provide additional cues for the parasite scape from the host. For example, VSGs and parasite DNA containing CpG, present in EVs, are recognized by SRA and Toll-like receptor 9, respectively. These interactions could potentiate a strong immune response and modulate macrophage and dendritic cells to activate TNF- $\alpha$, IL-6, and IL-12 (Stijlemans et al., 2016). T. brucei EVs are also proposed to modulate changes in the vascular endothelium (Varikuti et al., 2020).

Additionally, microvesicles (MVs) isolated from T. brucei infected hosts induce a progression meningo-encephalitic late stage (S2), inflammatory processes and modulation in astrocytes that resembled the one produced by IFN- $\gamma$, a central mechanism in HAT pathogenesis (Dozio et al., 2019).

T. brucei has at least two types of EVs. One, that is continuously released by the parasite, and the other that occurs upon parasite stress, as those affecting RNA transcription and processing. In these parasites, pre-mRNAs are transcribed through long polycistronic gene arrays and further processed by trans-splicing with a spliced leader (SL) exon and by polyadenylation (Clayton, 2019). The spliced leader (SL) RNA is processed in the cytosol and upon trans-splicing inhibition is incorporated into multivesicular bodies through the endosomal sorting complexes required for 
transport (ESCRT), in a similar way as microRNA is secreted in exosomes of mammalian cells. These exosomes have been shown to affect the motility pattern of the parasite itself (Eliaz et al., 2017). These EVs are internalized by insect form (procyclics of T. brucei in the insect host and are key components in the parasite-parasite communication. Taken together, the release of T. brucei EVs plays a role in cell-cell communication with the host and among themselves and open new insights to development new potential therapeutic targets or diagnostic markers.

\section{BIOGENESIS OF EVS IN TRYPANOSOMES}

Very little is known how the EVs are formed and biogenesis whether they are released in special situations, for example during parasite differentiation. Recently, it has been proposed that the parasite surface resembles a quilt with different types of surface proteins distributed in separate patches (Mucci et al., 2017). The GP85/ Trans-sialidase proteins form surface aggregates exclude the mucin-like glycoproteins and each patch might be enriched in different groups of EVs either as a consequence of their secretory pathway or biophysical properties (Niyogi et al., 2014). Therefore, it is expected that different EVs might coexist and affect differently the host cells. Many orthologs of the secretory machinery of eukaryote cells (ESCRT machinery) have been described in T. brucei (Silverman et al., 2013) and it was shown that inhibiting Vsp36 (an ESCRT component) compromises EVs secretion, but not of nanotube derived EVs (Eliaz et al., 2017). Therefore, different mechanisms of secretion may occur for these distinct types of particles that are also biochemically distinct and functions. How and whether the release of EVs from the membrane is regulated is still a matter of investigation.

\section{Leishmania EVs}

As well covered in the previous sections, parasites of the Leishmania genus -being also trypanosomatids are known to secrete proteins via their endoplasmic reticulum and Golgi apparatus (McConville et al., 2002; Corrales et al., 2010) and flagellar pocket (Field et al., 2007). In this context, several important virulence factors of Leishmania (e.g. Zinc-metalloprotease GP63 and LPG) can be released within the insect vector's gut and inoculated to the mammalian host during the sand fly's blood meal (Yao et al., 2003; Joshi et al., 2005). Markedly, as previously discussed for T. cruzi and T. brucei, Leishmania parasites require a nonconventional protein secretion system to release proteins lacking a signal peptide. In this way, exosomes have been found to be a selective and efficient pathway for proteins to leave Leishmania (Théry et al., 2009; Atayde et al., 2015). In fact, the great majority of Leishmania species studied to date revealed that only 5-9\% of exosomal proteins have a signal peptide (Silverman et al., 2008; Atyame Nten et al., 2010; Geiger et al., 2010).

Since 2008, several studies reported the release of exosomes by various species of Leishmania when cultured in vitro, as well as during their replication and development into metacyclic Leishmania promastigotes. Notably, in both cases, in vitro or in vivo produced Leishmania exosomes/EVs strongly contributed to enrich the parasite population with major virulence factors such as GP63. Moreover, exosomes have shown to alter myeloid cell signaling and microbicidal functions as strongly as whole promastigotes (Silverman et al., 2010a; Silverman et al., 2010b; Hassani et al., 2014; Atayde et al., 2015). The growing knowledge on leishmanial exosomes highlights the critical role of these extracellular vesicles not only in the infectious process but also in the progression of the parasites within the mammalian host leading to the various leishmaniasis-related pathologies.

Olivier's initial observation of GP63 clustered within vesicles being transferred to the macrophage led us to study whether Leishmania may produce EVs, thus including exosomes (Gomez et al., 2009; Gomez and Olivier, 2010). Markedly, studying the temperature-induced exoproteome of Leishmania mexicana, we obtained our first clear evidence demonstrating that Leishmania parasites can release small vesicles (Hassani et al., 2011). However, Reiner's laboratory was the first one to provide a clear demonstration of Leishmania parasites secreting well characterized exosomes (Silverman et al., 2010a).

During Olivier's lab first study, they found that by emulating the transition of the parasite from vector to the mammalian host, the temperature shift was inducing an increase of proteins secretion via exosome-like vesicles on the surface of the parasite. Proteomic analysis revealed that almost all Leishmania exosomal proteins lacking a signal peptide were secreted in a non-conventional manner (Hassani et al., 2011). Of utmost interest, it was found that those EVs showed similar capacities as whole promastigotes to hijack host macrophage signaling and functions, in part by inducing host phosphor-tyrosine protein (PTP) negative regulatory mechanisms. Using GP63-deficient Leishmania major parasites, we demonstrated that the absence of this virulence factor, which is greatly enriched in wild-type L. major exosomes, was almost completely abrogating their capacity to modulate host immune response comparatively to its wild-type counterpart (Hassani et al., 2014). This is different from L. infantum LPG1 -/- mutants, where the lack of this glycoconjugate did not affect NO and cytokine induction by its EVs (Nogueira et al., 2020). This further demonstrates the critical role played by Leishmania virulence factors enriched in leishmanial exosomes. Previous works reported by Silverman and colleagues were seminal to strengthen the role of Leishmania EVs as macrophage immunomodulators (Silverman et al., 2010a; Silverman et al., 2010b) such as for instance, to modify IFN $\gamma$-induced cytokines secretion by human monocytes cultured in the presence of L. donovani vesicles. Moreover, in an in vivo context, $\mathrm{CD} 4^{+}$ lymphocytes from mice inoculated with leishmanial exosomes were more prone to produce immunosuppressive cytokines (i.e. IL-10, IL4) and exacerbate pathology (Silverman et al., 2010b). More recently, EVs from New-World, dermotropic L. amazonensis were found to be more pro-inflammatory, triggering the production of NO, IL-6 and TNF- $\alpha$ in a TLR4/TLR2/NF- $\kappa B$-dependent fashion (Nogueira et al., 2020). On the other hand, in the same study, EVs from L. infantum and $L$. braziliensis were not able to induce significant levels of those cytokines (Nogueira et al., 2020) but induced IL-10 (Castelli et al., 2019). Although this study was in vitro, in vivo studies with L. amazonensis EVs in B-1 cells and L. infantum confirmed their pro-inflammatory activity (Barbosa et al., 2018; Perez-Cabezas et al., 
2019; Toledo et al., 2020). Pre-injection with EVs from those species induced cytokine production and increased parasite burden. Regarding L. infantum, proteomic analysis has suggested several molecules responsible for their functional activities (Santarem et al., 2013). However, a more detailed proteomic analysis was provided comparing procyclic and metacyclic-like forms (Forrest et al., 2020). Those analysis found approximately 50 virulence factors and some differentially expressed proteins in each stage. Most of the studies have focused on qualitative characterization of exoproteomes especially in L. infantum (Marshall et al., 2018). However, comparative exoproteome analysis from different Leishmania species are still scarce. For example, L. infantum and L. mexicana proteomics have been reported under the same conditions (Lynn et al., 2013). There is still a need for comparisons including a wider panel of Leishmania species. Those will provide information on how polymorphisms in the EVs protein could affect parasite-host interplay in different clinical forms. Collectively those findings strongly support the paramount role of exosomes released by various Leishmania spp. to trigger major immunomodulatory actions favorable for guaranteeing the infection and survival of the parasites in their hosts.

In a parallel study, exosomes released by macrophages infected with L. mexicana were found to be solely enriched in GP63 in terms of Leishmania proteins, whereas, as expected, the rest of the proteins corresponded to those of the macrophage (Hassani and Olivier, 2013). Macrophage exosomes released in response to LPS and Leishmania stimulation were found to induce macrophage inflammatory genes slightly differently in comparison to exosomes derived from naïve macrophages, reinforcing that EVs released during infectious context could be more prone to induce inflammatory reaction in the host.

\section{Leishmania Exosomes and Sand Fly Midgut}

One critical matter in the field of EVs, is to realize that the great majority of the studies performed in various fields (i.e. immunology, cancer, stem cells) were conducted with vesicles isolates from biological fluids or from cell cultures. However, Olivier's team finally reported a pioneering finding showing that Leishmania EVs were being formed and freed within sand fly midgut and were delivered by Leishmania metacyclic promastigotes to the mammalian host during the blood feeding of the vector (Atayde et al., 2015). This co-transmission was revealed to be highly inflammatory in Balb/c mice and concurring to the development of hyper skin ulceration under a Th17-type response. Markedly, this study is the first to demonstrate Leishmania EVs enriched with GP63 are key sand fly-egested virulence factors, revealing Leishmania exosomes as critical infectious instruments for the proper development of leishmaniasis.

While L. major exosomes induce an IL-17a-mediated immune response (Atayde et al., 2015), Reiner and colleagues (Silverman et al., 2010a; Silverman et al., 2010b) found that IL-4 was a cardinal cytokine ruling over IL-17a in the exacerbation of skin inflammation. Of note, while in Reiner's study, this phenomenon was observed in a context where exosomes were used for vaccination first prior to the challenge with promastigotes, Olivier's lab experiments tried to mimic the physiological setup of the sand fly when taking a blood-meal and both exosomes and parasites are simultaneously transferred. Moreover, and according to previous reports, IL-17a is a very powerful signal to recruit neutrophil and to favor cutaneous leishmaniasis development in mouse and human skin pathology (Maurer et al., 2006; Boaventura et al., 2010; Griewank et al., 2014; Dietze-Schwonberg et al., 2019). Markedly, a study from Olivier's laboratory strongly supports that Leishmania EVs concur to neutrophil migration toward the inoculation site (Hassani et al., 2014). Finally, several derived-insect components and parasite/ bacteria were shown to be important during the sand fly bite (Dey et al., 2018). Those induced IL-1 $\beta$ induction via inflammasome by neutrophils and were important for $L$. donovani visceralization. Although a mixture of different components is found in the inoculum, the solely role of EVs in this process is an open field to be explored.

\section{Hijack of Leishmania Exosomes by LRV1 Endovirus}

Over the last 10 years, there have been several reports showing that certain Leishmania species belonging to the Viannia subgenus, which are lower eukaryotic organisms, can be infected by viruses. For instance. L. (V.) guyanensis is known to be infected by the endovirus Leishmania RNA Virus 1 (LRV1) (Guilbride et al., 1992; Stuart et al., 1992). Of note, this viral culprit within Leishmania was found to exacerbate the development of mucocutaneous leishmaniasis due to its capacity to trigger a strong TLR3/TLR7dependent inflammatory response, which directly correlates with an enhancement in Leishmania metastatic behavior that is characteristic of mucocutaneous leishmaniasis (Ives et al., 2011). Consequently, understanding how this virus is transmitted is a critical step towards a better comprehension of not only Leishmania pathogenesis but also virus evolution and adaptation mechanisms.

Of interest, it is believed that LRV1 virus can propagate within $L$. (V.) guyanensis during their division, as well as to influence the host immune cells while dead parasites release the non-enveloped form of the virus (Olivier, 2011). While this remains a potential mechanism of viral propagation, some other pathways could be involved in such complex process. Olivier's team recent observations using both in vitro cultures and in vivo sand fly vector approaches, showed that Leishmania promastigotes can actively produce and release exosomes in natural condition. Based on this discovery, they further investigated whether LRV1 could exploit Leishmania exosomal pathway to safely exit the promastigotes. Of utmost interest, they found that $30 \%$ of the exosomes released by L. (V.) guyanensis contained the whole LRV1 endovirus, conferring the virus protection against the different adverse conditions that it will encounter in the external milieu (Atayde et al., 2019a; Olivier and Fernandez-Prada, 2019). Additionally, LRV1 "exosomal shield" favored the virus to efficiently infect naïve Leishmania $(V$.) spp., which naturally fuse to and integrate EVs content to potentially gain information, as reported for T. brucei (Eliaz et al., 2017). However, in this case, naïve parasites rapidly become virally infected and see their level of infectivity modified, as previously discussed. In addition, LRV1 contained within Leishmania exosomes were found to be 
responsible for the TLR3-dependent induction of inflammasome and exacerbation of L. (V.) guyanensis infection (Barrias et al., 2019; Olivier and Zamboni, 2020).

Of note, although viral particles and exosomes are very alike, they share several physical and structural similitudes. A variety of viruses infecting humans have been found to use host-cell exosomes as vessels for transporting their nuclear materials and capsids, also impacting the overall viral pathogenesis and virus-induced subsequent pathologies (Meckes and Raab-Traub, 2011; Alenquer and Amorim, 2015). However, LRV1 using Leishmania exosomes is the first demonstration of exosomes harboring a whole virion. Overall, it is clear that Leishmania parasites of the Viannia subgenus and their LRV1 endovirus represent an impressive mutualistic relationship in which both entities are interconnected by exosomes.

\section{Leishmania Exosomes in Drug Resistant Parasites}

Control of leishmaniasis is based on a very short list of chemotherapeutic agents headed by pentavalent antimonials, followed by miltefosine and amphotericin B. These drugs are far from ideal due to host toxicity, elevated cost, limited access, and high rates of drug resistance (Leprohon et al., 2015; Olivier and Fernandez-Prada, 2019; Saha et al., 2020). As leishmaniasis is a vector-transmitted disease, the spread of drug-resistant parasites is ultimately dependent on their transmission potential for which within- and between-host ecology plays a key role. Markedly, as discussed through all this review, EVs play a major role in all these transmission/interaction events. Considering that the molecular content of eukaryotic EVs is a fingerprint of the origin cell reflecting its physiological/functional status, Fernandez-Prada's laboratory recently explored the composition of leishmanial EVs in the context of drug resistance, in collaboration with Olivier's group (Douanne et al., 2020). This was the first study describing $L$. infantum EVs' core proteome, as well as all those proteins specifically enriched in EVs released by antimony-, miltefosineand amphotericin-resistant parasites. Fernandez-Prada's work showed for the first time that drug-resistance mechanisms can induce changes in the morphology, size, and distribution of EVs in Leishmania, with drug-resistant parasites releasing larger vesicles when compared to the wild-type counterpart (especially amphotericin B-resistant parasites with vesicles larger than 200 $\mathrm{nm}$ ). Of note, several virulence factors (i.e. GP63), putative transcription factors (i.e. $\mathrm{CBF} / \mathrm{NF}-\mathrm{Y}$ ), as well as proteins encoded by drug-resistance genes (i.e. antimony drug-resistance gene $m r p A$ (Douanne et al., 2020) were identified among drugspecific enriched proteins. In relation to these last, MDR transporters were shown to transmitted from drug-resistant to drug-sensitive tumor cells by exosomes in vivo and in vitro (LopesRodrigues et al., 2016), which points to a possible similar mechanism of drug-resistance transmission in Leishmania parasites. Currently ongoing and future studies will bring new knowledge on how EVs released by drug-resistant parasites contribute to drug resistance and, in a more general context, to the survival of Leishmania parasites through all the stressful conditions encountered during their life cycle.

\section{FUTURE APPLICATIONS AND THERAPEUTIC USE OF HOST AND TRYPANOSOMATID EVs}

One major challenge for the near future is the development of new and improved therapies for the treatment and prevention of diseases caused by trypanosomes. The EVs from these parasites can offer new potential developments for diagnosis, follow-up of treatment responses, monitoring disease progression and determining the prognosis. EVs can also be helpful in devising new vaccine targets. For example, we have found that immunization mice with T. cruzi EVs obtained from trypomastigotes can be induce protection against experimental Chagas disease (unpublished). Nevertheless, the molecules found in EVs responsible for this protection are yet to be determined and will in turn, represent novel biomarkers. In addition, EVs isolated from patients can be a biomarker during early clinical stage, acute and chronic phase. These EVs can be associated with clinical stage or allow the follow up in clinical trials new drugs. Further investigation of these EVs regarding the micro-RNA and long coding RNA, for example, could provide relevant information about Chagas's disease progression in humans. We have started to compare the circulating EVs isolated from plasma from patients with Chronic Chagas Disease (CCD). The plasma from CCD released less EVs with differences in their ability to induce cytokine production. CCD patients EVs were able to induce a differential production of IFN- $\gamma$ and IL-17 in relation to controls, with differences being more evident in earlier/less severe stages of the disease (Madeira et al., 2020 submitted).

\section{CONCLUSIONS}

EVs studies increase every year, since they represent valuable biological markers (Table 1) with a powerful diagnostic and therapy function. Several works published in the literature show that the EVs released by trypanosomatids might play a fundamental role in the pathogenesis of CD, HAT and several Leishmania species and in the host's immune response to the parasite (Trocoli Torrecilhas et al., 2009; Cestari et al., 2012; Torrecilhas et al., 2012; Santarem et al., 2013; Hassani et al., 2014; Atayde et al., 2015; Nogueira et al., 2015; Barbosa et al., 2018; Ribeiro et al., 2018; Toledo et al., 2020). These major effects are depicted in Figure 2. However, little is known about the mechanisms involved in the EV release process and whether this occurs as a result of damage to the parasite. In addition, the understanding of the relationship between different strains of T. cruzi (with different degrees of virulence) in the infectious process and in the production of EVs is still scarce. The same is valid for the different species of Leishmania that cause different type of diseases. Therefore, more studies are needed, to understand the EVs role in the pathogenesis of these parasitic endemic diseases, as well as in the mechanisms of pathogen-host interaction. This may be the starting point for the development of new preventive and therapeutic strategies with more efficient pharmacological targets against these parasitic which continues difficult to prevent, and treat and, whose current available drugs are toxic and not completely effective. The papers published in the 


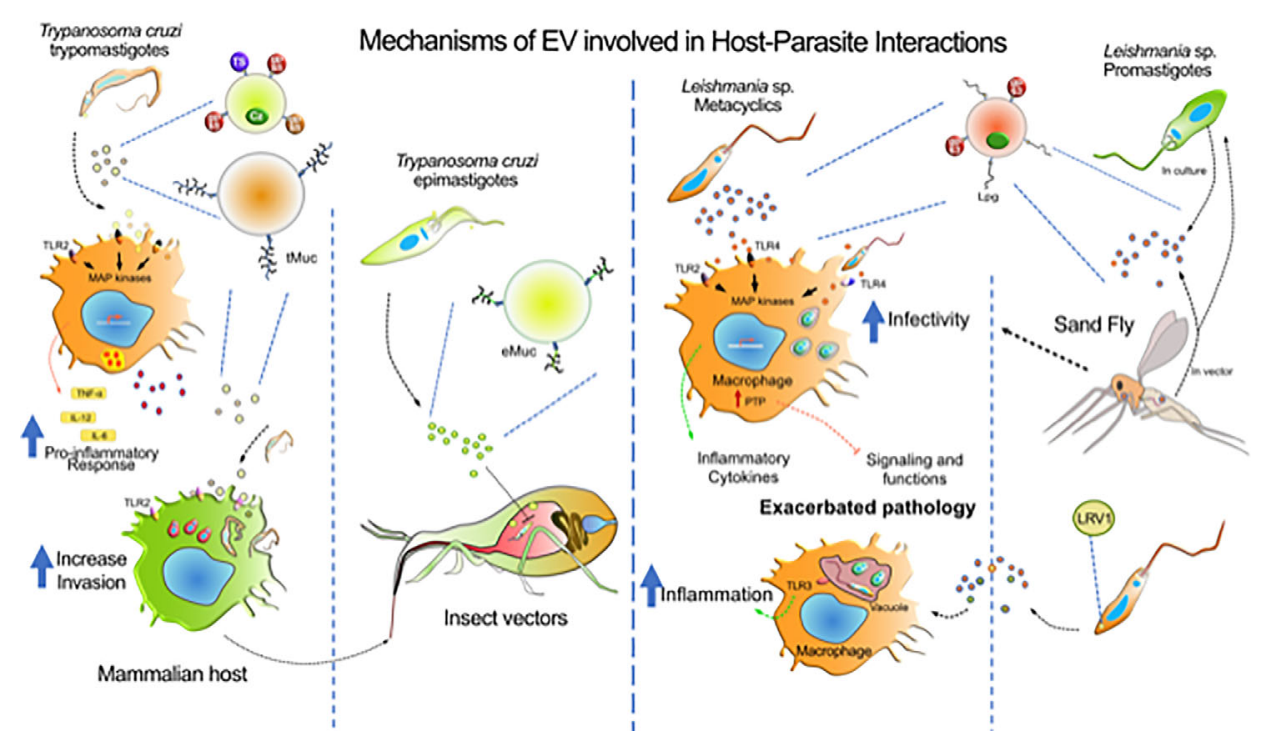

FIGURE 2 | Mechanisms of EV involved in host-parasite interactions. The diagram represents the major contributions of EVs from T. cruzi, Leishmania sp. and host cells during the infection by these parasites. T. cruzi release heterogeneous populations of EVs containing surface mucin-like glycoproteins (tMuc and eMuc), GPI anchored proteins (GP63 protease, GP85, and TS superfamily members) and soluble proteins (cruzipain, Cz), which interact with macrophages through TLR2 receptors which activate MAP kinases and induce a pro-inflammatory response (TNF- $\alpha$, IL-12, and IL-6). Macrophages also release EVs that might affect the host immune system. The TLR2 - T. cruzi EVs interaction enhances further parasite invasion. In the insect vector, the parasite epimastigote EVs delays translocation of parasites through intestine. Leishmania metacyclics release EVs enriched with GP63 and LPG, that could interact with macrophages via TLRs and, depending on the species, to induce pro- and anti-inflammatory responses. GP63-enriched EVs were found to induce host protein tyrosine phosphatases concurring to alter macrophage signaling and microbicidal functions. However, receptors involved in EVs recognition concurring to augment infection of phagocytes is still not identify. Leishmania virus (LRV1) incorporate within Leishmania exosomes was found to induce myeloid cells (macrophage, neutrophil) inflammasome in a TLR-dependent fashion concurring to exacerbate skin pathology. Leishmania exosomes are released in the gut of the sand Fly vector and have been found to be co-inoculated with promastigotes during blood meal. Revealing that this co-inoculation can exacerbate myeloid cells infection and skin pathology development.

literature, so far, show the important role that these vesicles play in the infectivity and in the modulation of the host's immune response by the parasite, however the study in this field still has some gaps to be filled, mainly in functional biological aspects that allow a better understanding of the mechanisms and conditions for the release of these vesicles. Therefore, more studies are needed, as one of the fundamental points for the control of endemic parasitic diseases is the understanding of mechanisms involving the pathogenhost interaction.

\section{AUTHOR CONTRIBUTIONS}

All authors have been equally involved in writing and editing. Figures have been done by SS and AT, and edited in addition by

\section{REFERENCES}

Abels, E. R., and Breakefield, X. O. (2016). Introduction to Extracellular Vesicles: Biogenesis, RNA Cargo Selection, Content, Release, and Uptake. Cell Mol. Neurobiol. 36, 301-312. doi: 10.1007/s10571-016-0366-Z

Acosta, D. M., Soprano, L. L., Ferrero, M. R., Esteva, M. I., Riarte, A., Couto, A. S., et al. (2012). Structural and immunological characterization of sulphatides: relevance of sulphate moieties in Trypanosoma cruzi glycoconjugates. Parasite Immunol. 34, 499-510. doi: 10.1111/j.1365-3024.2012.01378.x
MO. All authors contributed to the article and approved the submitted version.

\section{FUNDING}

This work was supported by the SS and ACT FAPESP 2019/159090 ), ACT CNPq (408186/2018-6) and CAPES. Research in Olivier Lab is funded by grants from the Canadian Institute of Health Research (CIHR grant No. 159765) and the Natural Sciences and Engineering Research Council of Canada (NSERC). Research in Fernandez-Prada Lab is funded by a Natural Sciences and Engineering Research Council of Canada Discovery Grant RGPIN-2017-04480 and by the Canada foundation for Innovation (www.innovation.ca), grant number 37324.
Akers, J. C., Gonda, D., Kim, R., Carter, B. S., and Chen, C. C. (2013). Biogenesis of extracellular vesicles (EV): exosomes, microvesicles, retrovirus-like vesicles, and apoptotic bodies. J. Neurooncol. 113, 1-11. doi: 10.1007/s11060-013-1084-8

Albertti, L. A., Macedo, A. M., Chiari, E., Andrews, N. W., and Andrade, L. O. (2010). Role of host lysosomal associated membrane protein (LAMP) in Trypanosoma cruzi invasion and intracellular development. Microbes Infect. 12, 784-789. doi: 10.1016/j.micinf.2010.05.015

Alenquer, M., and Amorim, M. J. (2015). Exosome Biogenesis, Regulation, and Function in Viral Infection. Viruses 7, 5066-5083. doi: 10.3390/v7092862 
Alisson-Silva, F., Mantuano, N. R., Lopes, A. L., Vasconcelos-Dos-Santos, A., Vale, A. M., Costa, M. M., et al. (2019). CD43 sialoglycoprotein modulates cardiac inflammation and murine susceptibility to Trypanosoma cruzi infection. Sci. Rep. 9, 8628. doi: 10.1038/s41598-019-45138-7

Almeida, I. C., and Gazzinelli, R. T. (2001). Proinflammatory activity of glycosylphosphatidylinositol anchors derived from Trypanosoma cruzi: structural and functional analyses. J. Leukoc. Biol. 70, 467-477.

Almeida, I. C., Gazzinelli, R., Ferguson, M. A., and Travassos, L. R. (1999). Trypanosoma cruzi mucins: potential functions of a complex structure. Mem. Inst. Oswaldo Cruz 94, 173-176. doi: 10.1590/s0074-02761999000700023

Almeida, I. C., Camargo, M. M., Procópio, D. O., Silva, L. S., Mehlert, A., Travassos, L. R., et al. (2000). Highly purified glycosylphosphatidylinositols from Trypanosoma cruzi are potent proinflammatory agents. EMBO J. 19, 1476-1485. doi: 10.1093/ emboj/19.7.1476

Alvarez, V. E., Niemirowicz, G. T., and Cazzulo, J. J. (2012). The peptidases of Trypanosoma cruzi: digestive enzymes, virulence factors, and mediators of autophagy and programmed cell death. Biochim. Biophys. Acta 1824, 195-206. doi: 10.1016/j.bbapap.2011.05.011

Ancarola, M. E., Marcilla, A., Herz, M., Macchiaroli, N., Pérez, M., Asurmendi, S., et al. (2017). Cestode parasites release extracellular vesicles with microRNAs and immunodiagnostic protein cargo. Int. J. Parasitol. 47, 675-686. doi: 10.1016/j.ijpara.2017.05.003

Andrade, L. O., and Andrews, N. W. (2005). The Trypanosoma cruzi-host-cell interplay: location, invasion, retention. Nat. Rev. Microbiol. 3, 819-823. doi: $10.1038 /$ nrmicrol249

Andrade, L. O. (2019). Plasma membrane repair involvement in parasitic and other pathogen infections. Curr. Top. Membr. 84, 217-238. doi: 10.1016/ bs.ctm.2019.08.002

Andre, F., Andersen, M., Wolfers, J., Lozier, A., Raposo, G., Serra, V., et al. (2001). Exosomes in cancer immunotherapy: preclinical data. Adv. Exp. Med. Biol. 495, 349-354. doi: 10.1007/978-1-4615-0685-0_49

Araldi, E., Krämer-Albers, E. M., Hoen, E. N., Peinado, H., Psonka-Antonczyk, K. M., Rao, P., et al. (2012). International Society for Extracellular Vesicles: first annual meeting, April 17-21, 2012: ISEV-2012. J. Extracell. Vesicles 1, 19995. doi: 10.3402/jev.vli0.19995

Aresta-Branco, F., Erben, E., Papavasiliou, F. N., and Stebbins, C. E. (2019). Mechanistic Similarities between Antigenic Variation and Antibody Diversification during Trypanosoma brucei Infection. Trends Parasitol. 35, 302-315. doi: 10.1016/j.pt.2019.01.011

Assis, R. R., Ibraim, I. C., Noronha, F. S., Turco, S. J., and Soares, R. P. (2012). Glycoinositolphospholipids from Leishmania braziliensis and L. infantum: modulation of innate immune system and variations in carbohydrate structure. PLoS Negl. Trop. Dis. 6, e1543. doi: 10.1371/journal.pntd.0001543

Atayde, V. D., Aslan, H., Townsend, S., Hassani, K., Kamhawi, S., and Olivier, M. (2015). Exosome Secretion by the Parasitic Protozoan Leishmania within the Sand Fly Midgut. Cell Rep. 13, 957-967. doi: 10.1016/j.celrep.2015.09.058

Atayde, V. D., Hassani, K., da Silva Lira Filho, A., Borges, A. R., Adhikari, A., Martel, C., et al. (2016). Leishmania exosomes and other virulence factors: Impact on innate immune response and macrophage functions. Cell Immunol. 309, 7-18. doi: 10.1016/j.cellimm.2016.07.013

Atayde, V. D., da Silva Lira Filho, A., Chaparro, V., Zimmermann, A., Martel, C., Jaramillo, M., et al. (2019a). Exploitation of the Leishmania exosomal pathway by Leishmania RNA virus 1. Nat. Microbiol. 4, 714-723. doi: 10.1038/s41564-018-0352-y

Atayde, V. D., da Silva Lira Filho, A., Chaparro, V., Zimmermann, A., Martel, C., Jaramillo, M., et al. (2019b). Publisher Correction: Exploitation of the Leishmania exosomal pathway by Leishmania RNA virus 1. Nat. Microbiol. 4, 724. doi: 10.1038/s41564-019-0420-y

Atyame Nten, C. M., Sommerer, N., Rofidal, V., Hirtz, C., Rossignol, M., Cuny, G., et al. (2010). Excreted/secreted proteins from trypanosome procyclic strains. J. BioMed. Biotechnol. 2010:212817. doi: 10.1155/2010/212817

Barbosa, F. M. C., Dupin, T. V., Toledo, M. D. S., Reis, N., Ribeiro, K., CronembergerAndrade, A., et al. (2018). Extracellular Vesicles Released by Leishmania (Leishmania) amazonensis Promote Disease Progression and Induce the Production of Different Cytokines in Macrophages and B-1 Cells. Front. Microbiol. 9, 3056. doi: 10.3389/fmicb.2018.03056

Barrias, E., Reignault, L., de Carvalho, T. M. U., and de Souza, W. (2019). Clathrin coated pit dependent pathway for Trypanosoma cruzi internalization into host cells. Acta Trop. 199, 105057. doi: 10.1016/j.actatropica.2019.105057
Bastos, C. J., Aras, R., Mota, G., Reis, F., Dias, J. P., de Jesus, R. S., et al. (2010). Clinical outcomes of thirteen patients with acute chagas disease acquired through oral transmission from two urban outbreaks in northeastern Brazil. PLoS Negl. Trop. Dis. 4, e711. doi: 10.1371/journal.pntd.0000711

Bayer-Santos, E., Aguilar-Bonavides, C., Rodrigues, S. P., Cordero, E. M., Marques, A. F., Varela-Ramirez, A., et al. (2013). Proteomic analysis of Trypanosoma cruzi secretome: characterization of two populations of extracellular vesicles and soluble proteins. J. Proteome Res. 12, 883-897. doi: 10.1021/pr300947g

Becker, A., Thakur, B. K., Weiss, J. M., Kim, H. S., Peinado, H., and Lyden, D. (2016). Extracellular Vesicles in Cancer: Cell-to-Cell Mediators of Metastasis. Cancer Cell. 30, 836-848. doi: 10.1016/j.ccell.2016.10.009

Bern, C. (2015). Chaga's Disease. N. Engl. J. Med. 373, 456-466. doi: 10.1056/ NEJMra1410150

Boaventura, V. S., Santos, C. S., Cardoso, C. R., de Andrade, J., Dos Santos, W. L., Clarencio, J., et al. (2010). Human mucosal leishmaniasis: neutrophils infiltrate areas of tissue damage that express high levels of Th17-related cytokines. Eur. J. Immunol. 40, 2830-2836. doi: 10.1002/eji.200940115

Borges, B. C., Uehara, I. A., Dias, L. O., Brígido, P. C., da Silva, C. V., and Silva, M. J. (2016). Mechanisms of Infectivity and Evasion Derived from Microvesicles Cargo Produced by. Front. Cell Infect. Microbiol. 6, 161. doi: 10.3389/fcimb.2016.00161

Brutus, L., Schneider, D., Postigo, J., Romero, M., Santalla, J., and Chippaux, J. P. (2008). Congenital Chagas disease: diagnostic and clinical aspects in an area without vectorial transmission, Bermejo, Bolivia. Acta Trop. 106, 195-199. doi: 10.1016/j.actatropica.2008.03.009

Buchanan, K. T., Ames, J. B., Asfaw, S. H., Wingard, J. N., Olson, C. L., Campana, P. T., et al. (2005). A flagellum-specific calcium sensor. J. Biol. Chem. 280, 40104-40111. doi: 10.1074/jbc.M505777200

Burleigh, B. A., and Andrews, N. W. (1995a). A 120-kDa alkaline peptidase from Trypanosoma cruzi is involved in the generation of a novel $\mathrm{Ca}(2+)$-signaling factor for mammalian cells. J. Biol. Chem. 270, 5172-5180. doi: 10.1074/jbc.270.10.5172

Burleigh, B. A., and Andrews, N. W. (1995b). The mechanisms of Trypanosoma cruzi invasion of mammalian cells. Annu. Rev. Microbiol. 49, 175-200. doi: 10.1146/annurev.mi.49.100195.001135

Burleigh, B. A., and Andrews, N. W. (1998). Signaling and host cell invasion by Trypanosoma cruzi. Curr. Opin. Microbiol. 1, 461-465. doi: 10.1016/s13695274(98)80066-0

Burleigh, B. A., Caler, E. V., Webster, P., and Andrews, N. W. (1997). A cytosolic serine endopeptidase from Trypanosoma cruzi is required for the generation of Ca2+ signaling in mammalian cells. J. Cell Biol. 136, 609-620. doi: 10.1083/ jcb.136.3.609

Buscaglia, C. A., Campetella, O., Leguizamón, M. S., and Frasch, A. C. (1998). The repetitive domain of Trypanosoma cruzi trans-sialidase enhances the immune response against the catalytic domain. J. Infect. Dis. 177, 431-436. doi: 10.1086/ 514199

Buscaglia, C. A., Campo, V. A., Di Noia, J. M., Torrecilhas, A. C., De Marchi, C. R., Ferguson, M. A., et al. (2004). The surface coat of the mammal-dwelling infective trypomastigote stage of Trypanosoma cruzi is formed by highly diverse immunogenic mucins. J. Biol. Chem. 279, 15860-15869. doi: 10.1074/ jbc.M314051200

Buscher, P., Cecchi, G., Jamonneau, V., and Priotto, G. (2017). Human African trypanosomiasis. Lancet 390, 2397-2409. doi: 10.1016/S0140-6736(17)31510-6

Caeiro, L. D., Alba-Soto, C. D., Rizzi, M., Solana, M. E., Rodriguez, G., Chidichimo, A. M., et al. (2018). The protein family TcTASV-C is a novel Trypanosoma cruzi virulence factor secreted in extracellular vesicles by trypomastigotes and highly expressed in bloodstream forms. PLoS Negl. Trop. Dis. 12, e0006475. doi: 10.1371/journal.pntd.0006475

Caler, E. V., Vaena de Avalos, S., Haynes, P. A., Andrews, N. W., and Burleigh, B. A. (1998). Oligopeptidase B-dependent signaling mediates host cell invasion by Trypanosoma cruzi. EMBO J. 17, 4975-4986. doi: 10.1093/emboj/17.17.4975

Camargo, M. M., Almeida, I. C., Pereira, M. E., Ferguson, M. A., Travassos, L. R., and Gazzinelli, R. T. (1997). Glycosylphosphatidylinositol-anchored mucinlike glycoproteins isolated from Trypanosoma cruzi trypomastigotes initiate the synthesis of proinflammatory cytokines by macrophages. J. Immunol. 158, 5890-5901.

Campos, M. A., Almeida, I. C., Takeuchi, O., Akira, S., Valente, E. P., Procópio, D. O., et al. (2001). Activation of Toll-like receptor-2 by glycosylphosphatidylinositol anchors from a protozoan parasite. J. Immunol. 167, 416-423. doi: 10.4049/ jimmunol.167.1.416 
Campos, M. A., Rosinha, G. M., Almeida, I. C., Salgueiro, X. S., Jarvis, B. W., Splitter, G. A., et al. (2004). Role of Toll-like receptor 4 in induction of cellmediated immunity and resistance to Brucella abortus infection in mice. Infect. Immun. 72, 176-186. doi: 10.1128/iai.72.1.176-186.2004

Campos, J. H., Soares, R. P., Ribeiro, K., Andrade, A. C., Batista, W. L., and Torrecilhas, A. C. (2015). Extracellular Vesicles: Role in Inflammatory Responses and Potential Uses in Vaccination in Cancer and Infectious Diseases. J. Immunol. Res. 2015, 832057. doi: 10.1155/2015/832057

Castelli, G., Bruno, F., Saieva, L., Alessandro, R., Galluzzi, L., Diotallevi, A., et al. (2019). Exosome secretion by Leishmania infantum modulate the chemotactic behavior and cytokinic expression creating an environment permissive for early infection. Exp. Parasitol. 198, 39-45. doi: 10.1016/j.exppara.2019.01.014

Cavalcanti, D. P., Shimada, M. K., Probst, C. M., Souto-Padrón, T. C., de Souza, W., Goldenberg, S., et al. (2009). Expression and subcellular localization of kinetoplast-associated proteins in the different developmental stages of Trypanosoma cruzi. BMC Microbiol. 9, 120. doi: 10.1186/1471-2180-9-120

Cestari, I., Ansa-Addo, E., Deolindo, P., Inal, J. M., and Ramirez, M. I. (2012). Trypanosoma cruzi immune evasion mediated by host cell-derived microvesicles. J. Immunol. 188, 1942-1952. doi: 10.4049/jimmunol.1102053

Chaput, N., Andre, F., Schartz, N. E., Flament, C., Angevin, E., Escudier, B., et al. (2003a). [Exosomes and anti-tumour immunotherapy]. Bull. Cancer 90, 695-698.

Chaput, N., Schartz, N. E., Andre, F., and Zitvogel, L. (2003b). Exosomes for immunotherapy of cancer. Adv. Exp. Med. Biol. 532, 215-221. doi: 10.1007/ 978-1-4615-0081-0_17

Choudhuri, S., and Garg, N. J. (2020). PARP1-cGAS-NF-kappaB pathway of proinflammatory macrophage activation by extracellular vesicles released during Trypanosoma cruzi infection and Chagas disease. PLoS Pathog. 16, e1008474. doi: 10.1371/journal.ppat.1008474

Clayton, C. (2019). Regulation of gene expression in trypanosomatids: living with polycistronic transcription. Open Biol. 9:190072. doi: 10.1098/rsob.190072

Cordero, E. M., Cortez, C., Yoshida, N., and da Silveira, J. F. (2019). Signal peptide recognition in Trypanosoma cruzi GP82 adhesin relies on its localization at protein N-terminus. Sci. Rep. 9, 7325. doi: 10.1038/s41598-019-43743-0

Corrales, R. M., Sereno, D., and Mathieu-Daude, F. (2010). Deciphering the Leishmania exoproteome: what we know and what we can learn. FEMS Immunol. Med. Microbiol. 58, 27-38. doi: 10.1111/j.1574-695X.2009.00608.x

Cortez, C., Yoshida, N., Bahia, D., and Sobreira, T. J. (2012). Structural basis of the interaction of a Trypanosoma cruzi surface molecule implicated in oral infection with host cells and gastric mucin. PLoS One 7, e42153. doi: 10.1371/journal.pone.0042153

Cortez, C., Sobreira, T. J., Maeda, F. Y., and Yoshida, N. (2014). The gp82 surface molecule of Trypanosoma cruzi metacyclic forms. Subcell. Biochem. 74, 137150. doi: 10.1007/978-94-007-7305-9_6

Coura, J. R., and Vinas, P. A. (2010). Chagas disease: a new worldwide challenge. Nature 465, S6-S7. doi: 10.1038/nature09221

Crespin, M., Vidal, C., Picard, F., Lacombe, C., and Fontenay, M. (2009). Activation of PAK1/2 during the shedding of platelet microvesicles. Blood Coagul. Fibrinolysis 20, 63-70. doi: 10.1097/MBC.0b013e32831bc310

Cronemberger-Andrade, A., Xander, P., Soares, R. P., Pessoa, N. L., Campos, M. A., Ellis, C. C., et al. (2020). -Infected Human Macrophages Shed Proinflammatory Extracellular Vesicles That Enhance Host-Cell Invasion via Toll-Like Receptor 2. Front. Cell Infect. Microbiol. 10, 99. doi: 10.3389/fcimb.2020.00099

Cross, G. A., Kim, H. S., and Wickstead, B. (2014). Capturing the variant surface glycoprotein repertoire (the VSGnome) of Trypanosoma brucei Lister 427. Mol. Biochem. Parasitol. 195, 59-73. doi: 10.1016/j.molbiopara.2014.06.004

Cura, C. I., Lattes, R., Nagel, C., Gimenez, M. J., Blanes, M., Calabuig, E., et al. (2013). Early molecular diagnosis of acute Chagas disease after transplantation with organs from Trypanosoma cruzi-infected donors. Am. J. Transplant. 13, 3253-3261. doi: 10.1111/ajt.12487

Cwiklinski, K., de la Torre-Escudero, E., Trelis, M., Bernal, D., Dufresne, P. J., Brennan, G. P., et al. (2015). The Extracellular Vesicles of the Helminth Pathogen, Fasciola hepatica: Biogenesis Pathways and Cargo Molecules Involved in Parasite Pathogenesis. Mol. Cell Proteomics 14, 3258-3273. doi: 10.1074/mcp.M115.053934

da Silveira, J. F., Abrahamsohn, P. A., and Colli, W. (1979). Plasma membrane vesicles isolated from epimastigote forms of Trypanosoma cruzi. Biochim. Biophys. Acta 550, 222-232. doi: 10.1016/0005-2736(79)90209-8 de Carvalho, T. M., and de Souza, W. (1989). Early events related with the behaviour of Trypanosoma cruzi within an endocytic vacuole in mouse peritoneal macrophages. Cell Struct. Funct. 14, 383-392. doi: 10.1247/ csf. 14.383

De Pablos, L. M., Díaz Lozano, I. M., Jercic, M. I., Quinzada, M., Giménez, M. J., Calabuig, E., et al. (2016). The C-terminal region of Trypanosoma cruzi MASPs is antigenic and secreted via exovesicles. Sci. Rep. 6, 27293. doi: 10.1038/srep27293

de Pablos Torro, L. M., Retana Moreira, L., and Osuna, A. (2018). Extracellular Vesicles in Chagas Disease: A New Passenger for an Old Disease. Front. Microbiol. 9, 1190. doi: 10.3389/fmicb.2018.01190

Devhare, P. B., and Ray, R. B. (2018). Extracellular vesicles: Novel mediator for cell to cell communications in liver pathogenesis. Mol. Aspects Med. 60, 115-122. doi: 10.1016/j.mam.2017.11.001

Dey, R., Joshi, A. B., Oliveira, F., Pereira, L., Guimarães-Costa, A. B., Serafim, T. D., et al. (2018). Gut Microbes Egested during Bites of Infected Sand Flies Augment Severity of Leishmaniasis via Inflammasome-Derived IL-1 $\beta$. Cell Host Microbe 23, 134-143.e136. doi: 10.1016/j.chom.2017.12.002

Dias, J. C., Silveira, A. C., and Schofield, C. J. (2002). The impact of Chagas disease control in Latin America: a review. Mem. Inst. Oswaldo Cruz 97, 603-612. doi: 10.1590/s0074-02762002000500002

Dias, J. P., Bastos, C., Araújo, E., Mascarenhas, A. V., Martins Netto, E., Grassi, F., et al. (2008). Acute Chagas disease outbreak associated with oral transmission. Rev. Soc. Bras. Med. Trop. 41, 296-300. doi: 10.1590/s0037-86822008000300014

Diaz Lozano, I. M., De Pablos, L. M., Longhi, S. A., Zago, M. P., Schijman, A. G., and Osuna, A. (2017). Immune complexes in chronic Chagas disease patients are formed by exovesicles from Trypanosoma cruzi carrying the conserved MASP N-terminal region. Sci. Rep. 7, 44451. doi: 10.1038/srep44451

Dietze-Schwonberg, K., Lopez Kostka, S., Lorenz, B., Regen, T., Waisman, A., and von Stebut, E. (2019). IL-17A/F in Leishmania major-resistant C57BL/6 mice. Exp. Dermatol. 28, 321-323. doi: 10.1111/exd.13896

Douanne, N., Dong, G., Douanne, M., Olivier, M., and Fernandez-Prada, C. (2020). Unravelling the proteomic signature of extracellular vesicles released by drug-resistant Leishmania infantum parasites. PLoS Negl. Trop. Dis. 14, e0008439. doi: 10.1371/journal.pntd.0008439

Doyle, L. M., and Wang, M. Z. (2019). Overview of Extracellular Vesicles, Their Origin, Composition, Purpose, and Methods for Exosome Isolation and Analysis. Cells 8 (7), 727. doi: 10.3390/cells8070727

Dozio, V., Lejon, V., Mumba Ngoyi, D., Buscher, P., Sanchez, J. C., and Tiberti, N. (2019). Cerebrospinal Fluid-Derived Microvesicles From Sleeping Sickness Patients Alter Protein Expression in Human Astrocytes. Front. Cell Infect. Microbiol. 9, 391. doi: 10.3389/fcimb.2019.00391

Duschak, V. G., and Couto, A. S. (2009). Cruzipain, the major cysteine protease of Trypanosoma cruzi: a sulfated glycoprotein antigen as relevant candidate for vaccine development and drug target. A review. Curr. Med. Chem. 16, 31743202. doi: 10.2174/092986709788802971

Eickhoff, C. S., Giddings, O. K., Yoshida, N., and Hoft, D. F. (2010). Immune responses to gp82 provide protection against mucosal Trypanosoma cruzi infection. Mem. Inst. Oswaldo Cruz 105, 687-691. doi: 10.1590/s007402762010000500015

Eliaz, D., Kannan, S., Shaked, H., Arvatz, G., Tkacz, I. D., Binder, L., et al. (2017). Exosome secretion affects social motility in Trypanosoma brucei. PLoS Pathog. 13, e1006245. doi: 10.1371/journal.ppat.1006245

Elnaiem, D. A., Ward, R. D., and Young, P. E. (1994). Development of Leishmania chagasi (Kinetoplastida: Trypanosomatidae) in the second blood-meal of its vector Lutzomyia longipalpis (Diptera: Psychodidae). Parasitol. Res. 80, 414419. doi: 10.1007/BF00932379

Evans-Osses, I., Mojoli, A., Monguió-Tortajada, M., Marcilla, A., Aran, V., Amorim, M., et al. (2017). Microvesicles released from Giardia intestinalis disturb host-pathogen response in vitro. Eur. J. Cell Biol. 96, 131-142. doi: 10.1016/j.ejcb.2017.01.005

Fernandes, M. C., Andrade, L. R., Andrews, N. W., and Mortara, R. A. (2011a). Trypanosoma cruzi trypomastigotes induce cytoskeleton modifications during HeLa cell invasion. Mem. Inst. Oswaldo Cruz 106, 1014-1016. doi: 10.1590/ S0074-02762011000800019

Fernandes, M. C., Cortez, M., Flannery, A. R., Tam, C., Mortara, R. A., and Andrews, N. W. (2011b). Trypanosoma cruzi subverts the sphingomyelinase- 
mediated plasma membrane repair pathway for cell invasion. J. Exp. Med. 208, 909-921. doi: 10.1084/jem.20102518

Field, A. E., Wagage, S., Conrad, S. M., and Mosser, D. M. (2007). Reduced pathology following infection with transgenic Leishmania major expressing murine CD40 ligand. Infect. Immun. 75, 3140-3149. doi: 10.1128/IAI.00160-07

Forrest, D. M., Batista, M., Marchini, F. K., Tempone, A. J., and Traub-Cseko, Y. M. (2020). Proteomic analysis of exosomes derived from procyclic and metacycliclike cultured Leishmania infantum chagasi. J. Proteomics 227, 103902. doi: 10.1016/j.jprot.2020.103902

Freire-de-Lima, L., Alisson-Silva, F., Carvalho, S. T., Takiya, C. M., Rodrigues, M. M., DosReis, G. A., et al. (2010). Trypanosoma cruzi subverts host cell sialylation and may compromise antigen-specific CD8+ T cell responses. J. Biol. Chem. 285, 13388-13396. doi: 10.1074/jbc.M109.096305

Freitas, L. M., dos Santos, S. L., Rodrigues-Luiz, G. F., Mendes, T. A., Rodrigues, T. S., Gazzinelli, R. T., et al. (2011). Genomic analyses, gene expression and antigenic profile of the trans-sialidase superfamily of Trypanosoma cruzi reveal an undetected level of complexity. PLoS One 6, e25914. doi: 10.1371/journal.pone. 0025914

Garcia-Silva, M. R., das Neves, R. F., Cabrera-Cabrera, F., Sanguinetti, J., Medeiros, L. C., Robello, C., et al. (2014). Extracellular vesicles shed by Trypanosoma cruzi are linked to small RNA pathways, life cycle regulation, and susceptibility to infection of mammalian cells. Parasitol. Res. 113, 285-304. doi: 10.1007/ s00436-013-3655-1

Geiger, A., Hirtz, C., Becue, T., Bellard, E., Centeno, D., Gargani, D., et al. (2010). Exocytosis and protein secretion in Trypanosoma. BMC Microbiol. 10, 20. doi: 10.1186/1471-2180-10-20

Gomez, M. A., and Olivier, M. (2010). Proteases and phosphatases during Leishmania-macrophage interaction: paving the road for pathogenesis. Virulence 1, 314-318. doi: 10.4161/viru.1.4.12194

Gomez, M. A., Contreras, I., Halle, M., Tremblay, M. L., McMaster, R. W., and Olivier, M. (2009). Leishmania GP63 alters host signaling through cleavageactivated protein tyrosine phosphatases. Sci. Signal. 2, ra58. doi: 10.1126/ scisignal.2000213

Gonçalves, M. F., Umezawa, E. S., Katzin, A. M., de Souza, W., Alves, M. J., Zingales, B., et al. (1991). Trypanosoma cruzi: shedding of surface antigens as membrane vesicles. Exp. Parasitol. 72, 43-53. doi: 10.1016/0014-4894(91) 90119-H

Griewank, K. G., Lorenz, B., Fischer, M. R., Boon, L., Lopez Kostka, S., and von Stebut, E. (2014). Immune modulating effects of NKT cells in a physiologically low dose Leishmania major infection model after alphaGalCer analog PBS57 stimulation. PLoS Negl. Trop. Dis. 8, e2917. doi: 10.1371/journal.pntd.0002917

Guilbride, L., Myler, P. J., and Stuart, K. (1992). Distribution and sequence divergence of LRV1 viruses among different Leishmania species. Mol. Biochem. Parasitol. 54, 101-104. doi: 10.1016/0166-6851(92)90099-6

Hassani, K., and Olivier, M. (2013). Immunomodulatory impact of leishmaniainduced macrophage exosomes: a comparative proteomic and functional analysis. PLoS Negl. Trop. Dis. 7, e2185. doi: 10.1371/journal.pntd.0002185

Hassani, K., Antoniak, E., Jardim, A., and Olivier, M. (2011). Temperatureinduced protein secretion by Leishmania mexicana modulates macrophage signalling and function. PLoS One 6, e18724. doi: 10.1371/journal.pone. 0018724

Hassani, K., Shio, M. T., Martel, C., Faubert, D., and Olivier, M. (2014). Absence of metalloprotease GP63 alters the protein content of Leishmania exosomes. PLoS One 9, e95007. doi: 10.1371/journal.pone.0095007

Herwaldt, B. L. (1999). Leishmaniasis. Lancet 354, 1191-1199. doi: 10.1016/S01406736(98) 10178-2

Hessvik, N. P., and Llorente, A. (2018). Current knowledge on exosome biogenesis and release. Cell Mol. Life Sci. 75, 193-208. doi: 10.1007/s00018-017-2595-9

Ichikawa, K. (2015). Synergistic effect of blocking cancer cell invasion revealed by computer simulations. Math. Biosci. Eng. 12, 1189-1202. doi: 10.3934/ mbe.2015.12.1189

Ives, A., Ronet, C., Prevel, F., Ruzzante, G., Fuertes-Marraco, S., Schutz, F., et al. (2011). Leishmania RNA virus controls the severity of mucocutaneous leishmaniasis. Science 331, 775-778. doi: 10.1126/science.1199326

Izquierdo, L., Acosta-Serrano, A., Mehlert, A., and Ferguson, M. A. (2015). Identification of a glycosylphosphatidylinositol anchor-modifying $\beta 1-3$ galactosyltransferase in Trypanosoma brucei. Glycobiology 25, 438-447. doi: $10.1093 /$ glycob/cwu131
Joshi, M. B., Rogers, M. E., Shakarian, A. M., Yamage, M., Al-Harthi, S. A., Bates, P. A., et al. (2005). Molecular characterization, expression, and in vivo analysis of LmexCht1: the chitinase of the human pathogen, Leishmania mexicana. J. Biol. Chem. 280, 3847-3861. doi: 10.1074/jbc.M412299200

Kandasamy, K., Mohan, S. S., Raju, R., Keerthikumar, S., Kumar, G. S., Venugopal, A. K., et al. (2010). NetPath: a public resource of curated signal transduction pathways. Genome Biol. 11, R3. doi: 10.1186/gb-2010-11-1-r3

Kao, C. Y., and Papoutsakis, E. T. (2019). Extracellular vesicles: exosomes, microparticles, their parts, and their targets to enable their biomanufacturing and clinical applications. Curr. Opin. Biotechnol. 60, 89-98. doi: 10.1016/ j.copbio.2019.01.005

Kaye, P., and Scott, P. (2011). Leishmaniasis: complexity at the host-pathogen interface. Nat. Rev. Microbiol. 9, 604-615. doi: 10.1038/nrmicro2608

Kim, D. K., Lee, J., Kim, S. R., Choi, D. S., Yoon, Y. J., Kim, J. H., et al. (2015). EVpedia: a community web portal for extracellular vesicles research. Bioinformatics 31, 933-939. doi: 10.1093/bioinformatics/btu741

Kima, P. E., Burleigh, B., and Andrews, N. W. (2000). Surface-targeted lysosomal membrane glycoprotein-1 (Lamp-1) enhances lysosome exocytosis and cell invasion by Trypanosoma cruzi. Cell Microbiol. 2, 477-486. doi: 10.1046/ j.1462-5822.2000.00071.x

Lantos, A. B., Carlevaro, G., Araoz, B., Ruiz Diaz, P., delos Milagros Camara, M., Buscaglia, C. A., et al. (2016). Sialic Acid Glycobiology Unveils Trypanosoma cruzi Trypomastigote Membrane Physiology. PLoS Pathog. 12, e1005559. doi: 10.1371/journal.ppat.1005559

Leprohon, P., Fernandez-Prada, C., Gazanion, E., Monte-Neto, R., and Ouellette, M. (2015). Drug resistance analysis by next generation sequencing in Leishmania. Int. J. Parasitol. Drugs Drug Resist. 5, 26-35. doi: 10.1016/ j.ijpddr.2014.09.005

Li, Q., Yang, X. H., Xu, F., Sharma, C., Wang, H. X., Knoblich, K., et al. (2013). Tetraspanin CD151 plays a key role in skin squamous cell carcinoma. Oncogene 32, 1772-1783. doi: 10.1038/onc.2012.205

Lopes-Rodrigues, V., Di Luca, A., Sousa, D., Seca, H., Meleady, P., Henry, M., et al. (2016). Multidrug resistant tumour cells shed more microvesicle-like EVs and less exosomes than their drug-sensitive counterpart cells. Biochim. Biophys. Acta 1860, 618-627. doi: 10.1016/j.bbagen.2015.12.011

Lovo-Martins, M. I., Malvezi, A. D., Zanluqui, N. G., Lucchetti, B. F. C., Tatakihara, V. L. H., Morking, P. A., et al. (2018). Extracellular Vesicles Shed By Trypanosoma cruzi Potentiate Infection and Elicit Lipid Body Formation and PGE2 Production in Murine Macrophages. Front. Immunol. 9:896. doi: 10.3389/fimmu.2018.00896

Luna, E. J., Furucho, C. R., Silva, R. A., Wanderley, D. M., Carvalho, N. B., Satolo, C. G., et al. (2017). Prevalence of Trypanosoma cruzi infection among Bolivian immigrants in the city of Sao Paulo, Brazil. Mem. Inst. Oswaldo Cruz 112, 7074. doi: 10.1590/0074-02760160384

Lynn, M. A., Marr, A. K., and McMaster, W. R. (2013). Differential quantitative proteomic profiling of Leishmania infantum and Leishmania mexicana density gradient separated membranous fractions. J. Proteomics 82, 179-192. doi: 10.1016/j.jprot.2013.02.010

Marcilla, A., Martin-Jaular, L., Trelis, M., de Menezes-Neto, A., Osuna, A., Bernal, D., et al. (2014). Extracellular vesicles in parasitic diseases. J. Extracell. Vesicles 3, 25040. doi: $10.3402 /$ jev.v3.25040

Marshall, S., Kelly, P. H., Singh, B. K., Pope, R. M., Kim, P., Zhanbolat, B., et al. (2018). Extracellular release of virulence factor major surface protease via exosomes in Leishmania infantum promastigotes. Parasit. Vectors 11, 355. doi: 10.1186/s13071-018-2937-y

Martin-Jaular, L., Nakayasu, E. S., Ferrer, M., Almeida, I. C., and Del Portillo, H. A. (2011). Exosomes from Plasmodium yoelii-infected reticulocytes protect mice from lethal infections. PLoS One 6, e26588. doi: 10.1371/journal.pone.0026588

Mathivanan, S., Ji, H., and Simpson, R. J. (2010). Exosomes: extracellular organelles important in intercellular communication. J. Proteomics 73, 19071920. doi: 10.1016/j.jprot.2010.06.006

Maurer, M., Lopez Kostka, S., Siebenhaar, F., Moelle, K., Metz, M., Knop, J., et al. (2006). Skin mast cells control T cell-dependent host defense in Leishmania major infections. FASEB J. 20, 2460-2467. doi: 10.1096/fj.06-5860com

McConville, M. J., Homans, S. W., Thomas-Oates, J. E., Dell, A., and Bacic, A. (1990). Structures of the glycoinositolphospholipids from Leishmania major. A family of novel galactofuranose-containing glycolipids. J. Biol. Chem. 265, 7385-7394. 
McConville, M. J., Mullin, K. A., Ilgoutz, S. C., and Teasdale, R. D. (2002). Secretory Pathway of Trypanosomatid Parasites. Microbiol. Mol. Biol. Rev. 66, 122-154. doi: 10.1128/mmbr.66.1.122-154.2002

Meckes, D. G.Jr., and Raab-Traub, N. (2011). Microvesicles and viral infection. J. Virol. 85, 12844-12854. doi: 10.1128/JVI.05853-11

Monteiro, A. C., Schmitz, V., Svensjo, E., Gazzinelli, R. T., Almeida, I. C., Todorov, A., et al. (2006). Cooperative activation of TLR2 and bradykinin B2 receptor is required for induction of type 1 immunity in a mouse model of subcutaneous infection by Trypanosoma cruzi. J. Immunol. 177, 6325-6335. doi: 10.4049/ jimmunol.177.9.6325

Morty, R. E., Lonsdale-Eccles, J. D., Morehead, J., Caler, E. V., Mentele, R., Auerswald, E. A., et al. (1999). Oligopeptidase B from Trypanosoma brucei, a new member of an emerging subgroup of serine oligopeptidases. J. Biol. Chem. 274, 26149-26156. doi: 10.1074/jbc.274.37.26149

Mucci, J., Lantos, A. B., Buscaglia, C. A., Leguizamon, M. S., and Campetella, O. (2017). The Trypanosoma cruzi Surface, a Nanoscale Patchwork Quilt. Trends Parasitol. 33 (2), 102-112. doi: 10.1016/j.pt.2016.10.004

Mugnier, M. R., Stebbins, C. E., and Papavasiliou, F. N. (2016). Masters of Disguise: Antigenic Variation and the VSG Coat in Trypanosoma brucei. PLoS Pathog. 12, e1005784. doi: 10.1371/journal.ppat.1005784

Neira, I., Ferreira, A. T., and Yoshida, N. (2002). Activation of distinct signal transduction pathways in Trypanosoma cruzi isolates with differential capacity to invade host cells. Int. J. Parasitol. 32, 405-414. doi: 10.1016/s0020-7519(02) 00004-8

Neira, I., Silva, F. A., Cortez, M., and Yoshida, N. (2003). Involvement of Trypanosoma cruzi metacyclic trypomastigote surface molecule gp82 in adhesion to gastric mucin and invasion of epithelial cells. Infect. Immun. 71, 557-561. doi: 10.1128/iai.71.1.557-561.2003

Niyogi, S., Mucci, J., Campetella, O., and Docampo, R. (2014). Rab11 regulates trafficking of trans-sialidase to the plasma membrane through the contractile vacuole complex of Trypanosoma cruzi. PLoS Pathog. 10, e1004224. doi: 10.1371/journal.ppat.1004224

Nóbrega, A. A., Garcia, M. H., Tatto, E., Obara, M. T., Costa, E., Sobel, J., et al. (2009). Oral transmission of Chagas disease by consumption of açaí palm fruit, Brazil. Emerg. Infect. Dis. 15, 653-655. doi: 10.3201/eid1504.081450

Nogueira, P. M., Ribeiro, K., Silveira, A. C., Campos, J. H., Martins-Filho, O. A., Bela, S. R., et al. (2015). Vesicles from different Trypanosoma cruzi strains trigger differential innate and chronic immune responses. J. Extracell. Vesicles 4, 28734. doi: 10.3402/jev.v4.28734

Nogueira, P. M., de Menezes-Neto, A., Borges, V. M., Descoteaux, A., Torrecilhas, A. C., Xander, P., et al. (2020). Immunomodulatory Properties of Leishmania Extracellular Vesicles During Host-Parasite Interaction: Differential Activation of TLRs and NF- $\kappa \mathrm{B}$ Translocation by Dermotropic and Viscerotropic Species. Front. Cell. Infect. Microbiol. 10, 380. doi: 10.3389/fcimb.2020.00380

Ofir-Birin, Y., and Regev-Rudzki, N. (2019). Extracellular vesicles in parasite survival. Science 363, 817-818. doi: 10.1126/science.aau4666

Ofir-Birin, Y., Heidenreich, M., and Regev-Rudzki, N. (2017). Pathogen-derived extracellular vesicles coordinate social behaviour and host manipulation. Semin. Cell Dev. Biol. 67, 83-90. doi: 10.1016/j.semcdb.2017.03.004

Olivier, M., and Fernandez-Prada, C. (2019). Leishmania and its exosomal pathway: a novel direction for vaccine development. Future Microbiol. 14, 559-561. doi: 10.2217/fmb-2019-0087

Olivier, M., and Zamboni, D.S. (2020). Leishmania Viannia guyanensis, LRV1 virus and extracellular vesicles: a dangerous trio influencing the faith of immune response during muco-cutaneous leishmaniasis. Curr. Opin. Immunol. 66, 108-113. doi: 10.1016/j.coi.2020.08.004

Olivier, M., Atayde, V. D., Isnard, A., Hassani, K., and Shio, M. T. (2012). Leishmania virulence factors: focus on the metalloprotease GP63. Microbes Infect. 14, 1377-1389. doi: 10.1016/j.micinf.2012.05.014

Olivier, M. (2011). Host-pathogen interaction: Culprit within a culprit. Nature 471, 173-174. doi: 10.1038/471173a

Paranaiba, L. F., Guarneri, A. A., Torrecilhas, A. C., Melo, M. N., and Soares, R. P. (2019). Extracellular vesicles isolated from Trypanosoma cruzi affect early parasite migration in the gut of Rhodnius prolixus but not in Triatoma infestans. Mem. Inst. Oswaldo Cruz 114, e190217. doi: 10.1590/0074-02760190217

Perez, C. J., Lymbery, A. J., and Thompson, R. C. A. (2015). Reactivation of Chagas Disease: Implications for Global Health. Trends Parasitol. 31, 595-603. doi: 10.1016/j.pt.2015.06.006
Perez-Cabezas, B., Cecilio, P., Gaspar, T. B., Gartner, F., Vasconcellos, R., and Cordeiro-da-Silva, A. (2019). Understanding Resistance vs. Susceptibility in Visceral Leishmaniasis Using Mouse Models of Leishmania infantum Infection. Front. Cell Infect. Microbiol. 9, 30. doi: 10.3389/fcimb.2019.00030

Peters, N. C., Egen, J. G., Secundino, N., Debrabant, A., Kimblin, N., Kamhawi, S., et al. (2008). In vivo imaging reveals an essential role for neutrophils in leishmaniasis transmitted by sand flies. Science 321, 970-974. doi: 10.1126/ science. 1159194

Pontes de Carvalho, L. C., Tomlinson, S., Vandekerckhove, F., Bienen, E. J., Clarkson, A. B., Jiang, M. S., et al. (1993). Characterization of a novel transsialidase of Trypanosoma brucei procyclic trypomastigotes and identification of procyclin as the main sialic acid acceptor. J. Exp. Med. 177, 465-474. doi: 10.1084/jem.177.2.465

Ponte-Sucre, A. (2016). An Overview of Trypanosoma brucei Infections: An Intense Host-Parasite Interaction. Front. Microbiol. 7, 2126. doi: 10.3389/ fmicb.2016.02126

Procópio, D. O., Almeida, I. C., Torrecilhas, A. C., Cardoso, J. E., Teyton, L., Travassos, L. R., et al. (2002). Glycosylphosphatidylinositol-anchored mucinlike glycoproteins from Trypanosoma cruzi bind to CD1d but do not elicit dominant innate or adaptive immune responses via the CD1d/NKT cell pathway. J. Immunol. 169, 3926-3933. doi: 10.4049/jimmunol.169.7.3926

Rak, J. (2010). Microparticles in cancer. Semin. Thromb. Hemost. 36, 888-906. doi: 10.1055/s-0030-1267043

Ramirez, M. I., Deolindo, P., de Messias-Reason, I. J., Arigi, E. A., Choi, H., Almeida, I. C., et al. (2017). Dynamic flux of microvesicles modulate parasitehost cell interaction of Trypanosoma cruzi in eukaryotic cells. Cell Microbiol. 19. doi: $10.1111 / \mathrm{cmi} .12672$

Raposo, G., and Stoorvogel, W. (2013). Extracellular vesicles: exosomes, microvesicles, and friends. J. Cell Biol. 200, 373-383. doi: 10.1083/ jcb. 201211138

Record, M., Poirot, M., and Silvente-Poirot, S. (2014). Emerging concepts on the role of exosomes in lipid metabolic diseases. Biochimie 96, 67-74. doi: 10.1016/ j.biochi.2013.06.016

Record, M. (2014). Intercellular communication by exosomes in placenta: a possible role in cell fusion? Placenta 35, 297-302. doi: 10.1016/ j.placenta.2014.02.009

Regev-Rudzki, N., Wilson, D. W., Carvalho, T. G., Sisquella, X., Coleman, B. M., Rug, M., et al. (2013). Cell-cell communication between malaria-infected red blood cells via exosome-like vesicles. Cell 153, 1120-1133. doi: 10.1016/ j.cell.2013.04.029

Reignault, L. C., Alcantara, C. L., Barrias, E. S., and de Souza, W. (2019). 3D reconstruction of Trypanosoma cruzi-macrophage interaction shows the recruitment of host cell organelles towards parasitophorous vacuoles during its biogenesis. J. Struct. Biol. 205, 133-146. doi: 10.1016/j.jsb.2018.12.010

Retana Moreira, L., Rodriguez Serrano, F., and Osuna, A. (2019). Extracellular vesicles of Trypanosoma cruzi tissue-culture cell-derived trypomastigotes: Induction of physiological changes in non-parasitized culture cells. PLoS Negl. Trop. Dis. 13, e0007163. doi: 10.1371/journal.pntd.0007163

Ribeiro, K. S., Vasconcellos, C. I., Soares, R. P., Mendes, M. T., Ellis, C. C., Aguilera-Flores, M., et al. (2018). Proteomic analysis reveals different composition of extracellular vesicles released by two. J. Extracell. Vesicles 7, 1463779. doi: 10.1080/20013078.2018.1463779

Ries, J., Komarek, A., Gottschalk, J., Brand, B., Amsler, L., Jutzi, M., et al. (2016). A Case of Possible Chagas Transmission by Blood Transfusion in Switzerland. Transfus. Med. Hemother. 43, 415-417. doi: 10.1159/000446264

Rodrigues, J. P. F., Sant'ana, G. H. T., Juliano, M. A., and Yoshida, N. (2017). Inhibition of Host Cell Lysosome Spreading by Trypanosoma cruzi Metacyclic Stage-Specific Surface Molecule gp90 Downregulates Parasite Invasion. Infect. Immun. 85 (9), e00302-17. doi: 10.1128/IAI.00302-17

Rossi, I. V., Gavinho, B., and Ramirez, M. I. (2019). Isolation and Characterization of Extracellular Vesicles Derived from Trypanosoma cruzi. Methods Mol. Biol. 1955, 89-104. doi: 10.1007/978-1-4939-9148-8_7

Rudenko, G. (2011). African trypanosomes: the genome and adaptations for immune evasion. Essays Biochem. 51, 47-62. doi: 10.1042/bse0510047

Ruiz, R. C., Rigoni, V. L., Gonzalez, J., and Yoshida, N. (1993). The 35/50 kDa surface antigen of Trypanosoma cruzi metacyclic trypomastigotes, and adhesion molecule involved in host cell invasion. Parasite Immunol. 15, 121-125. doi: 10.1111/j.1365-3024.1993.tb00591.x 
Saha, A., Bhattacharjee, A., Vij, A., Das, P. K., Bhattacharya, A., and Biswas, A. (2020). Evaluation of Modulators of cAMP-Response in Terms of Their Impact on Cell Cycle and Mitochondrial Activity of Leishmania donovani. Front. Pharmacol. 11, 782. doi: 10.3389/fphar.2020.00782

Santarem, N., Racine, G., Silvestre, R., Cordeiro-da-Silva, A., and Ouellette, M. (2013). Exoproteome dynamics in Leishmania infantum. J. Proteomics 84, 106118. doi: 10.1016/j.jprot.2013.03.012

Santori, F. R., Dorta, M. L., Juliano, L., Juliano, M. A., da Silveira, J. F., Ruiz, R. C., et al. (1996). Identification of a domain of Trypanosoma cruzi metacyclic trypomastigote surface molecule gp82 required for attachment and invasion of mammalian cells. Mol. Biochem. Parasitol. 78, 209-216. doi: 10.1016/s01666851(96)02626-6

Scharfstein, J., and Lima, A. P. (2008). Roles of naturally occurring protease inhibitors in the modulation of host cell signaling and cellular invasion by Trypanosoma cruzi. Subcell. Biochem. 47, 140-154. doi: 10.1007/978-0-38778267-6_11

Schenkman, S., and Eichinger, D. (1993). Trypanosoma cruzi trans-sialidase and cell invasion. Parasitol. Today 9, 218-222. doi: 10.1016/0169-4758(93)90017-a

Schenkman, S., Yoshida, N., and Cardoso de Almeida, M. L. (1988). Glycophosphatidylinositol-anchored proteins in metacyclic trypomastigotes of Trypanosoma cruzi. Mol. Biochem. Parasitol. 29, 141-151. doi: 10.1016/ 0166-6851(88)90069-2

Schenkman, S., Kurosaki, T., Ravetch, J. V., and Nussenzweig, V. (1992). Evidence for the participation of the Ssp-3 antigen in the invasion of nonphagocytic mammalian cells by Trypanosoma cruzi. J. Exp. Med. 175, 1635-1641. doi: 10.1084 /jem.175.6.1635

Schenkman, S., Ferguson, M. A., Heise, N., de Almeida, M. L., Mortara, R. A., and Yoshida, N. (1993). Mucin-like glycoproteins linked to the membrane by glycosylphosphatidylinositol anchor are the major acceptors of sialic acid in a reaction catalyzed by trans-sialidase in metacyclic forms of Trypanosoma cruzi. Mol. Biochem. Parasitol. 59, 293-303. doi: 10.1016/0166-6851(93)90227-o

Schenkman, S., Eichinger, D., Pereira, M. E., and Nussenzweig, V. (1994). Structural and functional properties of Trypanosoma trans-sialidase. Annu. Rev. Microbiol. 48, 499-523. doi: 10.1146/annurev.mi.48.100194.002435

Schneider, P., Rosat, J. P., Ransijn, A., Ferguson, M. A., and McConville, M. J. (1993). Characterization of glycoinositol phospholipids in the amastigote stage of the protozoan parasite Leishmania major. Biochem. J. 295 (Pt 2), 555-564. doi: 10.1042/bj2950555

Schwede, A., and Carrington, M. (2010). Bloodstream form Trypanosome plasma membrane proteins: antigenic variation and invariant antigens. Parasitology 137, 2029-2039. doi: 10.1017/S0031182009992034

Shikanai-Yasuda, M. A., and Carvalho, N. B. (2012). Oral transmission of Chagas disease. Clin. Infect. Dis. 54, 845-852. doi: 10.1093/cid/cir956

Silva, V. O., Maia, M. M., Torrecilhas, A. C., Taniwaki, N. N., Namiyama, G. M., Oliveira, K. C., et al. (2018). Extracellular vesicles isolated from Toxoplasma gondii induce host immune response. Parasite Immunol. 40, e12571. doi: $10.1111 /$ pim.12571

Silverman, J. M., Chan, S. K., Robinson, D. P., Dwyer, D. M., Nandan, D., Foster, L. J., et al. (2008). Proteomic analysis of the secretome of Leishmania donovani. Genome Biol. 9, R35. doi: 10.1186/gb-2008-9-2-r35

Silverman, J. M., Clos, J., de'Oliveira, C. C., Shirvani, O., Fang, Y., Wang, C., et al. (2010a). An exosome-based secretion pathway is responsible for protein export from Leishmania and communication with macrophages. J. Cell Sci. 123, 842852. doi: $10.1242 /$ jcs. 056465

Silverman, J. M., Clos, J., Horakova, E., Wang, A. Y., Wiesgigl, M., Kelly, I., et al. (2010b). Leishmania exosomes modulate innate and adaptive immune responses through effects on monocytes and dendritic cells. J. Immunol. 185, 5011-5022. doi: 10.4049/jimmunol.1000541

Silverman, J. S., Muratore, K. A., and Bangs, J. D. (2013). Characterization of the late endosomal ESCRT machinery in Trypanosoma brucei. Traffic 14, 10781090. doi: $10.1111 /$ tra.12094

Skotland, T., Hessvik, N. P., Sandvig, K., and Llorente, A. (2019). Exosomal lipid composition and the role of ether lipids and phosphoinositides in exosome biology. J. Lipid Res. 60, 9-18. doi: 10.1194/jlr.R084343

Soares, R. P., Torrecilhas, A. C., Assis, R. R., Rocha, M. N., Moura e Castro, F. A., Freitas, G. F., et al. (2012). Intraspecies variation in Trypanosoma cruzi GPImucins: biological activities and differential expression of $\alpha$-galactosyl residues. Am. J. Trop. Med. Hyg. 87, 87-96. doi: 10.4269/ajtmh.2012.12-0015
Soares, R. P., Xander, P., Costa, A. O., Marcilla, A., Menezes-Neto, A., Del Portillo, H., et al. (2017). Highlights of the São Paulo ISEV workshop on extracellular vesicles in cross-kingdom communication. J. Extracell. Vesicles 6, 1407213. doi: 10.1080/ 20013078.2017.1407213

Soprano, L. L., Parente, J. E., Landoni, M., Couto, A. S., and Duschak, V. G. (2018). Trypanosoma cruzi serinecarboxipeptidase is a sulfated glycoprotein and a minor antigen in human Chagas disease infection. Med. Microbiol. Immunol. 207, 117-128. doi: 10.1007/s00430-017-0529-7

Stijlemans, B., Caljon, G., Van Den Abbeele, J., Van Ginderachter, J. A., Magez, S., and De Trez, C. (2016). Immune Evasion Strategies of Trypanosoma brucei within the Mammalian Host: Progression to Pathogenicity. Front. Immunol. 7, 233. doi: 10.3389/fimmu.2016.00233

Stuart, K. D., Weeks, R., Guilbride, L., and Myler, P. J. (1992). Molecular organization of Leishmania RNA virus 1. Proc. Natl. Acad. Sci. U. S. A. 89, 8596-8600. doi: 10.1073/pnas.89.18.8596

Szempruch, A. J., Dennison, L., Kieft, R., Harrington, J. M., and Hajduk, S. L. (2016a). Sending a message: extracellular vesicles of pathogenic protozoan parasites. Nat. Rev. Microbiol. 14, 669-675. doi: 10.1038/nrmicro.2016.110

Szempruch, A. J., Sykes, S. E., Kieft, R., Dennison, L., Becker, A. C., Gartrell, A., et al. (2016b). Extracellular Vesicles from Trypanosoma brucei Mediate Virulence Factor Transfer and Cause Host Anemia. Cell 164, 246-257. doi: 10.1016/j.cell.2015.11.051

Théry, C., Zitvogel, L., and Amigorena, S. (2002). Exosomes: composition, biogenesis and function. Nat. Rev. Immunol. 2, 569-579. doi: 10.1038/nri855

Théry, C., Ostrowski, M., and Segura, E. (2009). Membrane vesicles as conveyors of immune responses. Nat. Rev. Immunol. 9, 581-593. doi: 10.1038/nri2567

Théry, C., Witwer, K. W., Aikawa, E., Alcaraz, M. J., Anderson, J. D., Andriantsitohaina, R., et al. (2018). Minimal information for studies of extracellular vesicles 2018 (MISEV2018): a position statement of the International Society for Extracellular Vesicles and update of the MISEV2014 guidelines. J. Extracell. Vesicles 7, 1535750. doi: 10.1080/20013078.2018.1535750

Toledo, M. D. S., Cronemberger-Andrade, A., Barbosa, F. M. C., Reis, N. F. C., Dupin, T. V., Soares, R. P., et al. (2020). Effects of extracellular vesicles released by peritoneal B-1 cells on experimental Leishmania (Leishmania) amazonensis infection. J. Leukoc. Biol. doi: 10.1002/JLB.3MA0220-464RR

Torrecilhas, A. C., Schumacher, R. I., Alves, M. J., and Colli, W. (2012). Vesicles as carriers of virulence factors in parasitic protozoan diseases. Microbes Infect. 14, 1465-1474. doi: 10.1016/j.micinf.2012.07.008

Trocoli Torrecilhas, A. C., Tonelli, R. R., Pavanelli, W. R., da Silva, J. S., Schumacher, R. I., de Souza, W., et al. (2009). Trypanosoma cruzi: parasite shed vesicles increase heart parasitism and generate an intense inflammatory response. Microbes Infect. 11, 29-39. doi: 10.1016/j.micinf.2008.10.003

Varikuti, S., Jha, B. K., Holcomb, E. A., McDaniel, J. C., Karpurapu, M., Srivastava, N., et al. (2020). The role of vascular endothelium and exosomes in human protozoan parasitic diseases. Vessel Plus 4, 28. doi: 10.20517/2574-1209.2020.27

Vexenat, J. A., de Castro, J. A., Cavalcante, R., Tavares, J. P., da Silva, M. R., Batista, W. H., et al. (1994). Visceral leishmaniasis in Teresina, State of Piaui, Brazil: preliminary observations on the detection and transmissibility of canine and sandfly infections. Mem. Inst. Oswaldo Cruz 89, 131-135. doi: 10.1590/s0074-02761994000200001

Vickerman, K., and Luckins, A. G. (1969). Localization of variable antigens in the surface coat of Trypanosoma brucei using ferritin conjugated antibody. Nature 224, 1125-1126. doi: 10.1038/2241125a0

Watanabe Costa, R., da Silveira, J. F., and Bahia, D. (2016). Interactions between Trypanosoma cruzi Secreted Proteins and Host Cell Signaling Pathways. Front. Microbiol. 7, 388. doi: 10.3389/fmicb. 2016.00388

WHO. (2019). Chagas disease (American trypanosomiasis). Available at: https:// www.who.int/health-topics/chagas-disease\#tab=tab_1.

Wolfers, J., Lozier, A., Raposo, G., Regnault, A., Théry, C., Masurier, C., et al. (2001). Tumor-derived exosomes are a source of shared tumor rejection antigens for CTL cross-priming. Nat. Med. 7, 297-303. doi: 10.1038/85438

Wyllie, M. P., and Ramirez, M. I. (2017). Microvesicles released during the interaction between Trypanosoma cruzi TcI and TcII strains and host blood cells inhibit complement system and increase the infectivity of metacyclic forms of host cells in a strain-independent process. Pathog. Dis. 75 (7). doi: 10.1093/femspd/ftx077

Yáñez-Mó, M., Siljander, P. R., Andreu, Z., Zavec, A. B., Borràs, F. E., Buzas, E. I., et al. (2015). Biological properties of extracellular vesicles and their physiological functions. J. Extracell. Vesicles 4, 27066. doi: 10.3402/jev.v4.27066 
Yao, C., Donelson, J. E., and Wilson, M. E. (2003). The major surface protease (MSP or GP63) of Leishmania sp. Biosynthesis, regulation of expression, and function. Mol. Biochem. Parasitol. 132, 1-16. doi: 10.1016/s0166-6851(03)00211-1

Yoshida, N., and Cortez, M. (2008). Trypanosoma cruzi: parasite and host cell signaling during the invasion process. Subcell. Biochem. 47, 82-91. doi: 10.1007/978-0-387-78267-6_6

Yoshida, N., Blanco, S. A., Araguth, M. F., Russo, M., and González, J. (1990). The stagespecific 90-kilodalton surface antigen of metacyclic trypomastigotes of Trypanosoma cruzi. Mol. Biochem. Parasitol. 39, 39-46. doi: 10.1016/0166-6851(90)90006-8

Zöller, M. (2009). Tetraspanins: push and pull in suppressing and promoting metastasis. Nat. Rev. Cancer 9, 40-55. doi: 10.1038/nrc2543
Conflict of Interest: The authors declare that the research was conducted in the absence of any commercial or financial relationships that could be construed as a potential conflict of interest.

Copyright (๑) 2020 Torrecilhas, Soares, Schenkman, Fernández-Prada and Olivier. This is an open-access article distributed under the terms of the Creative Commons Attribution License (CC BY). The use, distribution or reproduction in other forums is permitted, provided the original author(s) and the copyright owner(s) are credited and that the original publication in this journal is cited, in accordance with accepted academic practice. No use, distribution or reproduction is permitted which does not comply with these terms. 